Article

\title{
New Type of Sodium Alginate-g-acrylamide Polyelectrolyte Obtained by Electron Beam Irradiation: Characterization and Study of Flocculation Efficacy and Heavy Metal Removal Capacity
}

\author{
Gabriela Craciun, Elena Manaila * and Daniel Ighigeanu \\ National Institute for Laser, Plasma and Radiation Physics, Electron Accelerators Laboratory, \#409 \\ Atomistilor St., 077125 Magurele, Romania; gabriela.craciun@inflpr.ro (G.C.); daniel.ighigeanu@inflpr.ro (D.I.) \\ * Correspondence: elena.manaila@inflpr.ro; Tel.: +40-214-574-346
}

Received: 31 October 2018; Accepted: 22 January 2019; Published: 1 February 2019

check for updates

\begin{abstract}
The goals of the paper were first the obtainment and characterization of sodium alginate- $g$-acrylamide polyelectrolytes by electron beam irradiation in the range of 0.5 to $2 \mathrm{kGy}$, and second, the evaluation of flocculation efficacy and heavy metal removal capacity from aqueous solutions of known concentrations. Based on sodium alginate concentration, two types of grafted polymers were obtained. Physical, chemical, and structural investigations were performed. Flocculation studies under different stirring conditions on $0.5,0.1$ and $0.2 \%$ kaolin suspension were done. The removal capacity of $\mathrm{Cu}^{2+}$ and $\mathrm{Cr}^{6+}$ ions was also investigated. The acrylamide grafting ratio on sodium alginate backbone was found up to $2000 \%$ for samples containing $1 \%$ sodium alginate and up to $500 \%$ for samples containing $2 \%$ sodium alginate. Transmittances between 98 and $100 \%$ were obtained using, in the flocculation studies, polyelectrolytes containing $2 \%$ sodium alginate in concentrations of 0.5 and $1 \mathrm{ppm}$ on kaolin suspension of $0.1 \mathrm{wt} \%$. The polymer concentration was found critical for kaolin suspension of 0.05 and $0.1 \mathrm{wt} \%$. Polymers containing $1 \%$ sodium alginate were efficient in $\mathrm{Cr}^{6+}$ ion removal, while those containing $2 \%$ in $\mathrm{Cu}^{2+}$ ion removal.
\end{abstract}

Keywords: electron beam irradiation; grafting; flocculants

\section{Introduction}

Polyelectrolytes are water-soluble polymer carrying ionic charge along the polymer chain. They can be anionic or cationic and are available in a wide range of charge densities and molecular weights $[1,2]$. For at least forty years, their main applications in water treatment have been coagulation, flocculation, and dewatering of the sludge in treatment plants [3,4]. There are some advantages to their use in water and wastewater treatment, by comparing with the classic alum usage, such as: Dose requirements are notably lower, the formed flocs are much larger and stronger, the resulted sludge volumes are smaller, the phase separation between solid and water is considerably increased, the range of wastewaters that can be treated is wider, and last but not least, costs are up to $25-30 \%$ lower $[3,5,6]$. There are also disadvantages to their use, such as higher costs in particular situations or the sensitivity to incorrect dosage, but the most important is connected with the environment due to their synthetic constituents [3,6]. The influence of molecular structures on coagulation/flocculation, on the rates of both precipitation and sedimentation, on product water quality and on the solids content of the final sludge is still of great interest $[3,7,8]$. In water and wastewater treatment, the first and simplest step for solid particles removal is by gravity. Because particles with diameters on the order of $10 \mu \mathrm{m}$ are 
not settled down by gravity alone in an economically reasonable amount of time, a second process called coagulation, which consists of the destabilization of colloidal suspensions by neutralizing the electric forces that keep the suspended particles separated, is needed [9,10]. However, the aggregates formed in this process are small, strongly dependent on $\mathrm{pH}$ and its variations, and their sedimentation velocities are relatively low. The third process, called flocculation, which consists of the addition of inorganic/organic polymers, is necessary to be applied, sometimes even in conjunction with classical coagulants (salts of multivalent metals like aluminum and iron) $[9,10]$. Inorganic flocculants, very effective but usually used in very large quantities, leave large amounts of sludge and are strongly affected by $\mathrm{pH}$ changes. The organic flocculants, typically polymeric in nature, are not so effective, but some of them can be used even in ppm concentrations [9]. Among polymeric flocculants, the synthetic polymers can be tailor-made by controlling the molecular weight, molecular weight distribution, chemical structure of polymers, and nature and ratio of functional groups on polymeric backbone. Natural polymers, mainly polysaccharides, are fairly shear-stable in contrast with synthetic polymers, and biodegradable and easily available from reproducible farm or forest resources. The biodegradability of natural polymers reduces their shelf life and needs to be suitably controlled. It is, thus, evident that all polymers, whether natural or synthetic, have one or another disadvantage. Although attempts have been taking place for some time, the preoccupations to combine the best properties of natural and synthetic polymers are still topical [11-13]. Grafting is a useful method for modifying some properties of natural and synthetic polymers. In the grafting process [14-16], an amount of synthetic monomer is attached onto the polysaccharide backbone, the formed product providing properties from the base polymers and a number of new and favorable properties as shear stability [17-19]. It was envisaged [11,13] that by grafting flexible polyacrylamide chains on polysaccharides such as guar gum, xanthan gum, carboxy-methyl cellulose, and starch, it is possible to develop efficient, shear-stable, and potentially biodegradable flocculants for treatment of industrial effluents and mineral processing. In these flocculants, the flexible chains of polyacrylamide are grafted onto the rigid backbone of polysaccharides.

Even if the problem of colloidal suspensions or organic maters is solved by the existing methods, the presence of heavy metal still represents a challenge in the field of water and waste water treatment. These represent an ecotoxicological hazard of prime interest and increasing significance, because of their accumulation in living organisms [20,21]. For example, chromium and copper are very toxic metals even at low concentrations introduced into natural water from a variety of industrial wastes [20-22]. The chromium concentration that can be found in industrial waste water ranges from 0.5 to $270,000 \mathrm{mg} / \mathrm{L}$, while the tolerance limit for the discharge of $\mathrm{Cr}(\mathrm{VI})$ in surface water is $0.1 \mathrm{mg} / \mathrm{L}$, and in potable water $0.05 \mathrm{mg} / \mathrm{L}$ [20,21]. The permissible limit of copper ions in industrial effluents reported by USEPA is $1.3 \mathrm{mg} / \mathrm{L}$ and by WHO is maximum $2 \mathrm{mg} / \mathrm{L}$ [22]. A wide range of physical and chemical processes are available for both chromium and cooper ions removal from industrial wastewater, such as: Electrochemical precipitation, ultrafiltration, ion exchange, electrodialysis, reverse osmosis, chemical precipitation and adsorption for chromium and adsorption, cementation, membrane filtration, and electrodialysis or photocatalysis for cooper removal [20-22]. The major drawbacks with these processes are the high cost, toxic sludge generation or incomplete metal removal $[20,21]$. Because heavy metals cannot be biodegraded by microorganisms within the natural environment, the research and development of technologies that can remove these pollutants from water sources is currently a worldwide priority [23]. Consequently, there is an urgent need for the development of new flocculants and adsorbents having high flocculation and adsorption capacity and selectivity to remove heavy metal contaminants from aqueous media, and for this, grafted polymers are good candidates [24].

In the present study, the renewable and biodegradable alginate (a nontoxic, very user- and consumer-friendly polysaccharide) has been chosen to be grafted with polyacrylamide $[25,26]$. The goal of the paper is to present experimental results of the obtainment and characterization of a new type of polyelectrolyte, based on sodium alginate and acrylamide-sodium alginate-g-acrylamide. The electron 
beam irradiation in the range of 0.5 and $2 \mathrm{kGy}$ was used to obtain the polyelectrolyte. Characterizations were made by means of various physical and chemical methods in order to determine the conversion coefficient, residual monomer content, intrinsic viscosity, molecular weight, and radius of gyration. The radiation effect was evaluated through the Fourier transform infrared spectroscopy technique. By connecting the results with the behavior of water and acrylamide in radiation field in order to obtain polyacrylamide that is grafted on the alginate backbone, a possible reaction mechanism between monomer, polymer, and solvent was proposed. The polymer flocculation efficacy in terms of transmittance against distillated water was investigated by flocculation studies on kaolin suspension of $0.05,0.1$, and $0.2 \%$ under different stirring conditions. The use of the polyelectrolyte as a single metal system in order to remove heavy metal ions of $\mathrm{Cu}^{2+}$ and $\mathrm{Cr}^{6+}$ from water solutions having known concentrations was also a goal. The residual metal ion concentrations in the solutions after the flocculation tests were measured using the spectrophotometric method, and the results were expressed in terms of removal efficiency and absorption capacity after $24 \mathrm{~h}$.

\section{Experimental Section}

\subsection{Materials}

The materials used in experiments are shown in Table 1. Acrylamide (AMD), sodium alginate $(\mathrm{ALg})$, and potassium persulfate (PP, used as initiator) were purchased from Sigma Aldrich (Redox Group Company, Bucharest, Romania) and were used without further purification. All other reagents used for polyelectrolytes preparation and characterization were of analytical grade and used as received. The $\mathrm{Cu}^{2+}$ and $\mathrm{Cr}^{6+}$ metal ions used in the metal ion removal studies were provided as $\mathrm{CuSO}_{4}$ and $\mathrm{K}_{2} \mathrm{Cr}_{2} \mathrm{O}_{7}$ by Sigma Aldrich also. These reagents of analytical grade were prepared with double-distilled water [27].

Table 1. The materials used for polyelectrolytes preparation.

\begin{tabular}{clc}
\hline Materials & \multicolumn{1}{c}{$\begin{array}{c}\text { Chemical } \\
\text { Characteristics }\end{array}$} & $\begin{array}{c}\text { Chemical } \\
\text { Structure/Molecular Formula }\end{array}$ \\
\hline Acrylamide, AMD & $\begin{array}{l}\text { molecular weight: } 72.06 \mathrm{~g} / \mathrm{mol} ; \\
\text { density: } 1.051 \mathrm{~g} / \mathrm{cm}^{3} ; \\
\text { solubility in water: } 2.04 \mathrm{~kg} \cdot \mathrm{L}^{-1} \text { at } 25^{\circ} \mathrm{C} ;\end{array}$ & $\mathrm{H}_{2} \mathrm{C}=\mathrm{CH}-\mathrm{C}^{-} / \mathrm{NH}_{2}$ \\
\hline $\begin{array}{c}\text { Potassium persulfate, } \mathrm{PP} \\
\text { (used as reaction initiator) }\end{array}$ & $\begin{array}{l}\text { molecular weight: } 270.322 \mathrm{~g} / \mathrm{mol} ; \\
\text { density: } 2.477 \mathrm{~g} / \mathrm{cm}^{3} ; \\
\text { solubility in water: } 1.75 \mathrm{~g} / 100 \mathrm{~mL} \text { at } 0{ }^{\circ} \mathrm{C} ;\end{array}$ & $\mathrm{K}_{2} \mathrm{~S}_{2} \mathrm{O}_{8}$ \\
\hline Sodium alginate, $\mathrm{ALg}$ & $\begin{array}{l}\text { molecular weight: } 216.121 \mathrm{~g} / \mathrm{mol} ; \\
\text { density: } 1.601 \mathrm{~g} / \mathrm{cm}^{3} \\
\text { solubility in water: no more than } 2 \% \text { on the dried basis }\end{array}$ & $\begin{array}{c}\left.\mathrm{C}_{6} \mathrm{H}_{7} \mathrm{NaO}_{6}\right)_{\mathrm{n}} \text { or } \\
\mathrm{C}_{6} \mathrm{H}_{9} \mathrm{NaO}_{7}\end{array}$ \\
\hline
\end{tabular}

\subsection{Experimental Installation and Sample Preparation}

The polyelectrolytes were obtained in atmospheric conditions and at room temperature of $25^{\circ} \mathrm{C}$ by electron beam irradiation using the ALID-7 linear accelerator of travelling-wave type that was built in the Electron Accelerators Laboratory from the National Institute for Lasers, Plasma and Radiation Physics, Bucharest, Romania. The optimum values of the electron beam (EB) parameters, namely peak current $I_{\mathrm{EB}}$ and EB energy $E_{\mathrm{EB}}$, to produce maximum output power $P_{\mathrm{EB}}$ for a fixed pulse duration $\tau_{\mathrm{EB}}$ and repetition frequency $f_{\mathrm{EB}}$ are as follows: $E_{\mathrm{EB}}=5.5 \mathrm{MeV}, I_{\mathrm{EB}}=130 \mathrm{~mA}, P_{\mathrm{EB}}=670 \mathrm{~W}\left(f_{\mathrm{EB}}=250 \mathrm{~Hz}\right.$, $\left.\tau_{\mathrm{EB}}=3.75 \mu \mathrm{s}\right)$ [27].

The performance of irradiation process depends on the strict control of the absorbed dose $(D)$ and absorbed dose rate $\left(D^{*}\right)[27,28]$. In our experiments, the used electron beam dose rate was $3.5 \mathrm{kGy} / \mathrm{min}$ in order to accumulate doses between 0.5 and $2 \mathrm{kGy}$. For radiation dosimetry, the primary standard graphite calorimeter was used. The EB penetration depth was calculated in order to assure equal doses 
at the entry and exit of the irradiated samples. The thickness of a sample as a function of EB energy and sample density resulted as being $2 \mathrm{~cm}$, using the following formula [27,29]:

$$
E=2.6 \times t \times \rho+0.3
$$

where $E[\mathrm{MeV}]$ is the EB energy $(5.5 \mathrm{MeV}), t[\mathrm{~cm}]$ is the sample thickness, and $\rho\left[\mathrm{g} \cdot \mathrm{cm}^{-3}\right]$ is the sample density, in our case $1 \mathrm{~g} \cdot \mathrm{cm}^{-3}$.

Two types of monomeric solutions (AMD/ALg I, containing 1\% sodium alginate, and AMD/ALg II, containing $2 \%$ sodium alginate) were prepared and disposed for irradiation in polyvinylchloride (PVC) containers of a $3 \mathrm{~cm}$ diameter containing $15 \mathrm{~mL}$ of monomeric solutions.

\subsection{Sample Characterization}

\subsubsection{Physicochemical Characteristics}

To determine the conversion coefficient $(\mathrm{CC})$ and the residual monomer concentration $\left(\mathrm{M}_{\mathrm{r}}\right)$, 2 grams from each polymer called AMD/ALg I/0.5 to 2 and AMD/Alg II/0.5 to 2 were placed in $200 \mathrm{~mL}$ distilled water for 24 hours, then stirred for 1 hour at $400 \mathrm{rpm}$ for a very good mixing. CC and $\mathrm{M}_{\mathrm{r}}$ were determined using the titrimetric method, in which bromine reacts with the double bond of residual monomer. After complete dissolution in water, the polymers were treated excessively with a bromide-bromate solution, and the bromine excess was determined by means of the iodatometry method in the presence of sodium thiosulfate solution (1 M) [30-32]. The intrinsic viscosity $\left(\eta_{\text {intr. }}\right)$ was determined using the falling ball Hoppler viscometer of $\mathrm{BH}-2$ type $[30,33]$. The measured parameter is the ball falling time in the cylindrical tube inclined with 10 degrees against the vertical plane and filled with the liquid to be analyzed. The ball falling time through the polymeric solution was measured in five different concentrations. The working temperature was $30^{\circ} \mathrm{C}$ and sodium nitrate $1 \mathrm{~N}\left(\mathrm{NaNO}_{3}\right)$ was used as solvent.

The relative viscosity was calculated using the following relation:

$$
\eta_{\text {rel }}=\frac{t}{t_{0}}
$$

where $t$ is the falling time of the ball through the polymeric solution and $t_{0}$ is the falling time of the ball through the solvent.

The specific viscosity was calculated from the relation:

$$
\eta_{\mathrm{sp}}=\left(\eta_{\text {rel }}-1\right)
$$

The reduced viscosity was determined using the relation:

$$
\eta_{\text {red }}=\frac{\eta_{\mathrm{sp}}}{c}
$$

where $c$ is the polymer concentration $(\mathrm{g} / \mathrm{dL})$.

From the graphical representation of the $\eta_{\text {red }}$ as a function of the copolymer concentration, the intrinsic viscosity $\eta_{\text {intr }}$ was obtained by extrapolation.

\subsubsection{Purification of Grafted Polymers and Grafting Reaction Evaluation}

Different concentrations of polymerized mixtures from each sample were completely diluted in water, then added dropwise into a large excess of methanol $(150 \mathrm{~mL})$ in order to remove the homopolymer. The precipitated polymer was filtered off and washed with methanol 10 times $[30,34]$. Afterwards, it was precipitated by adding $250 \mathrm{~mL}$ of acetone in order to separate the unreacted monomer (acrylamide) from the grafted polymer, and finally it was dried in a hot air oven at 
$60{ }^{\circ} \mathrm{C}$ for $6 \mathrm{~h}$. The grafting ratio (\%) and grafting efficiency (\%) were calculated using the following relations [30,35-37]:

$$
\begin{gathered}
\text { Grafting ratio: } G R(\%)=\frac{w t . \text { of graft polymer }- \text { wt. of sodium alginate }}{w t . \text { of sodium alginate }} \times 100 \\
\text { Grafting efficiency: } G E(\%)=\frac{w t . \text { of graft polymer }- \text { wt. of sodium alginate }}{w t . \text { of monomer }} \times 100
\end{gathered}
$$

\subsubsection{FTIR Analysis and Reaction Mechanisms}

The polyelectrolyte chemical structure was investigated using the TENSOR 27 FTIR Spectrophotometer (Bruker, Bremen, Germany) by ATR measurement method. All the spectra were the average of 30 scans realized in absorption in the range of $4000-600 \mathrm{~cm}^{-1}$, with a resolution of $4 \mathrm{~cm}^{-1}$. By connecting the grafting reaction evaluation with the spectral analysis results, a reaction mechanism was realized.

\subsubsection{Flocculation Studies}

Flocculation studies were carried out on kaolin suspension, at room temperature of $25^{\circ} \mathrm{C}$ using the standard Jar test apparatus of Velp FC 6S type. The jar test apparatus having 6 stirrer blades that can rotate with a variable speed between 10 and $100 \mathrm{rpm}$ in 6 beakers of $500 \mathrm{~mL}$ was used in order to investigate the influence of the kaolin concentration $(0.05,0.1$, and $0.2 \mathrm{wt} \%)$, polymer concentration ( 0.5 to $10 \mathrm{ppm}$ ), and rotation speed (60 and $90 \mathrm{rpm}$ ) on the flocculation efficacy. Every sample was stirred for $15 \mathrm{~min}$ and then left to rest for another $15 \mathrm{~min}$ before sampling for analysis. Clear supernatant was drawn from the top layer (up to 1-2-cm depth), and its transmittance was measured at $620 \mathrm{~nm}$ using the Cary Bio-100 UV-VIS spectrophotometer (Agilrom Scientific SRL, Bucharest, Romania).

\subsubsection{Metal Ion Removal Studies}

Metal ion removal experiments were performed at room temperature in aqueous solutions containing concentrations of $500 \mathrm{mg} / \mathrm{L} \mathrm{Cu}^{2+}$ and $\mathrm{Cr}^{6+}$ ions. The metal ion concentrations in the solutions after treatment were measured by means of the spectrophotometric method using the Cary Bio-100 UV-VIS apparatus. The influence of the irradiation dose and sodium alginate concentration on removal efficiency and equilibrium absorption capacity was studied. The removal efficiency, $R(\%)$, and absorption capacity, $q_{e}$, after $24 \mathrm{~h}$ were calculated using the following equations [38-40]:

$$
\begin{gathered}
R(\%)=\frac{\left(C_{0}-C_{24}\right) \times 100}{C_{0}} \\
q_{24}(m g / g)=\frac{\left(C_{0}-C_{24}\right) \times V}{W}
\end{gathered}
$$

where $C_{0}$ and $C_{24}$ are the concentrations of metal ions in aqueous phase before and after $24 \mathrm{~h}$ of treatment $(\mathrm{mg} / \mathrm{L}), \mathrm{V}$ is the volume of the aqueous phase, and $W$ is the amount of flocculant.

\section{Results and Discussions}

Two types of aqueous solutions based on acrylamide and sodium alginate were prepared and subjected to electron beam (EB) irradiation in an atmospheric condition and at room temperature of $25^{\circ} \mathrm{C}$, in order to obtain grafted polymers having flocculation properties. Details concerning chemical composition and irradiation dose are given in Table 2. 
Table 2. The polyelectrolytes synthesis details.

\begin{tabular}{|c|c|c|c|c|}
\hline \multirow{2}{*}{ Samples Codes } & \multicolumn{3}{|c|}{ Amount of Chemicals } & \multirow{2}{*}{$\begin{array}{c}\text { Irradiation Dose } \\
(\mathbf{k G y})\end{array}$} \\
\hline & AMD (mol/L) & $\operatorname{Alg}(\%)$ & $\mathrm{PP}(\mathrm{mol} / \mathrm{L})$ & \\
\hline AMD/ALg I/0.5 & & & & 0.5 \\
\hline AMD/ALg I/0.75 & & & & 0.75 \\
\hline AMD/ALg I/1 & & & & 1 \\
\hline AMD/ALg I/1.25 & 2.63 & 1 & $9.25 \times 10^{-4}$ & 1.25 \\
\hline AMD/ALg I/1.5 & & & & 1.5 \\
\hline AMD/ALg I/1.75 & & & & 1.75 \\
\hline AMD/ALg I/2 & & & & 2 \\
\hline AMD/ALg II/0.5 & & & & 0.5 \\
\hline AMD/ALg II/0.75 & & & & 0.75 \\
\hline AMD/ALg II/1 & & & & 1 \\
\hline AMD/ALg II/1.25 & 2.63 & 2 & $9.25 \times 10^{-4}$ & 1.25 \\
\hline AMD/ALg II/1.5 & & & & 1.5 \\
\hline AMD/ALg II/1.75 & & & & 1.75 \\
\hline AMD/ALg II/2 & & & & 2 \\
\hline
\end{tabular}

\subsection{Physical and Chemical Characteristics of Sodium Alginate-g-acrylamide Polymers}

For the grafted polymers obtained as above, the conversion coefficient (CC), residual monomer concentration $\left(M_{\mathrm{r}}\right)$, and intrinsic viscosity $\left(\eta_{\text {intr. }}\right)$ were determined. The results are presented in Table 3 and Figure 1.

Table 3. Physical and chemical characteristics of sodium alginate-g-acrylamide polymers. AMD/ALg I (I) and AMD/ALg II (II).

\begin{tabular}{ccccccc}
\hline \multirow{2}{*}{ Dose (kGy) } & \multicolumn{2}{c}{$C_{\mathbf{c}} \mathbf{( \% )}$} & \multicolumn{2}{c}{$\boldsymbol{M}_{\text {rez. }} \mathbf{( \% )}$} & \multicolumn{2}{c}{$\eta_{\text {intr. }}(\mathbf{d} \mathbf{l} / \mathbf{g})$} \\
\cline { 2 - 6 } & $\mathbf{I}$ & II & I & II & I & II \\
\hline $\mathbf{0 . 5}$ & 83.21 & 83.04 & 0.0604 & 0.0675 & 1.516 & 0.822 \\
$\mathbf{0 . 7 5}$ & 90.76 & 90.41 & 0.0355 & 0.0369 & 1.880 & 1.172 \\
$\mathbf{1}$ & 92.54 & 92.99 & 0.0277 & 0.0269 & 2.081 & 1.790 \\
$\mathbf{1 . 2 5}$ & 93.64 & 93.94 & 0.0241 & 0.0227 & 1.625 & 1.632 \\
$\mathbf{1 . 5}$ & 95.39 & 94.69 & 0.0171 & 0.0199 & 1.491 & 1.532 \\
$\mathbf{1 . 7 5}$ & 96.97 & 96.51 & 0.0114 & 0.0135 & 1.469 & 1.301 \\
$\mathbf{2}$ & 96.58 & 96.72 & 0.0128 & 0.0128 & 1.403 & 1.283 \\
\hline
\end{tabular}

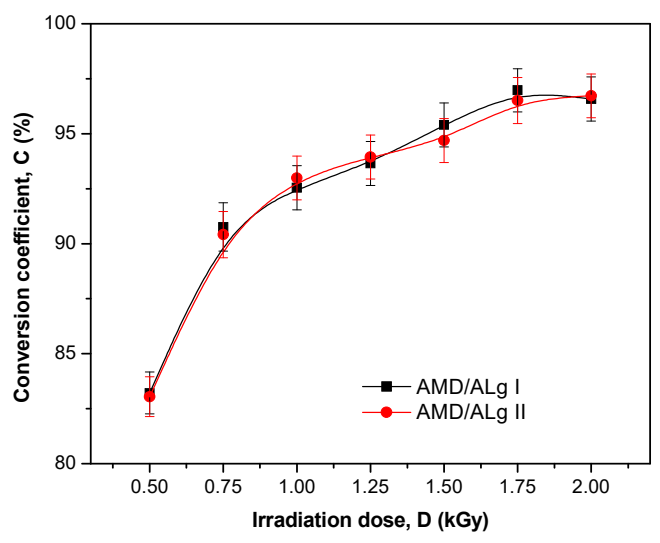

(a)

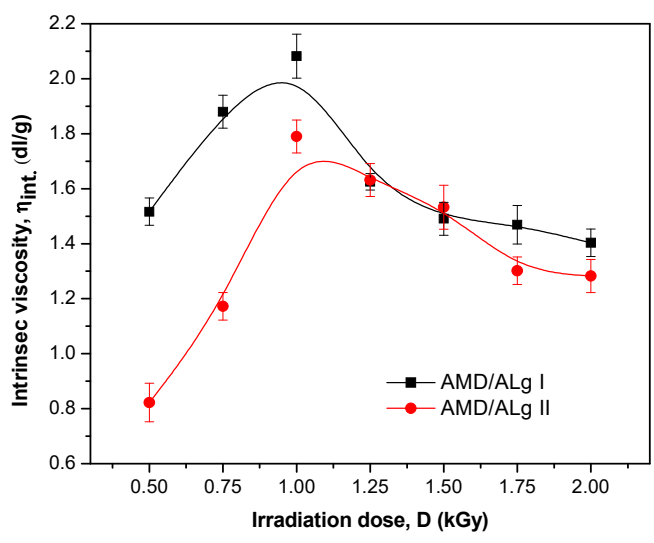

(b)

Figure 1. Conversion coefficient (a) and intrinsic viscosity (b) versus electron beam irradiation dose for AMD/ALg I and AMD/ALg II polymer types. 
In Table 3 and Figure $1 \mathrm{a}$, it can be seen that for both sodium alginate- $g$-acrylamide polymers, AMD/ALg I and AMD/ALg II, high conversion coefficients (up to $97 \%$ approximately) were obtained, correlated with low residual monomers contents (under $0.02 \%$ ) as the radiation dose increased. The increase of the irradiation dose increased the probability of higher molecular contact, resulting in the propagation of active chain and continuous CC increase [14,30,41]. Notable differences between the samples having different initial concentrations of sodium alginate cannot be observed.

The intrinsic viscosity (Figure $1 \mathrm{~b}$ ) presented a difference of $88 \%$ between samples having $1 \%$ and $2 \%$ sodium alginate content, these results being favorable for the first category up to the irradiation dose of $1.25 \mathrm{kGy}$. At the irradiation dose of 1.25 and $1.5 \mathrm{kGy}$, both AMD/ALg I and AMD/ALg II polymer types presented almost similar values, not under the values obtained at $0.5 \mathrm{kGy}$. Between 1.5 and $2 \mathrm{kGy}$, the values split apart again but not as in the initial range.

The effect of sodium alginate concentration and irradiation dose on the grafting reaction was investigated and then correlated with the FTIR analysis. The grafting ratio (GR) and grafting efficiency (GE) were calculated and plotted and the results are presented in Figure 2.

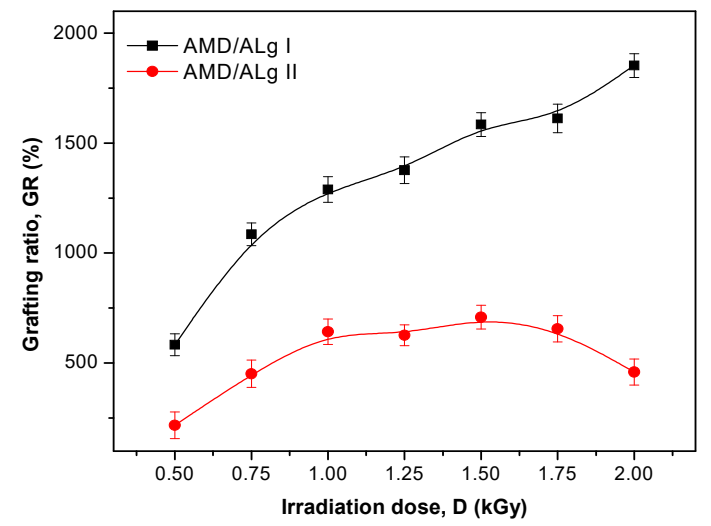

(a)

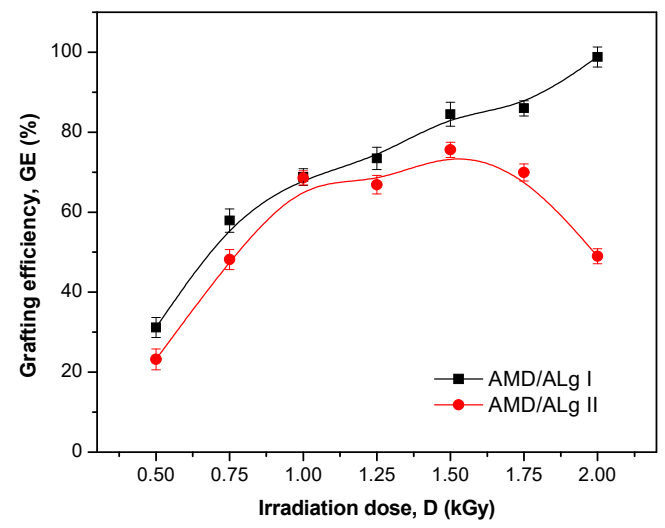

(b)

Figure 2. Grafting ratio (a) and grafting efficiency (b) as a function of sodium alginate concentration and irradiation dose.

As can be seen in Figure 2, doubling of the sodium alginate concentration leads to the decrease of both GR and GE. While the grafted polymers of AMD/ALg I type maintain an upward trend of both GR and GE, those of AMD/ALg II type presented maximum values at 1 and $1.5 \mathrm{kGy}$, and then GR and GE decreased. Thus, while the grafted polymers of AMD/ALg I type have GRs between $500 \%$ and $2000 \%$ depending on the irradiation dose, those of AMD/ALg II type just got up to $500 \%$. The grafting efficiencies of both AMD/ALg I and AMD/ALg II types are comparable up to $1 \mathrm{kGy}$, being around $65-70 \%$. Over this irradiation dose, the GEs of AMD/ALg I type increased up to $100 \%$, while the GEs of AMD/ALg II type showed a plateau region between 1 and $1.5 \mathrm{kGy}$ and then decreased.

As shown in Figures 1a and 2, CC increased with the irradiation dose increasing for both AMD/ALg I and AMD/ALg II polymer types, while GR and GE did not continue to rise for AMD/ALg II. Thus, we can say that differences in GR and GE appeared because of doubling the sodium alginate concentration, as long as the concentrations of PP and AMD were the same. The difference between initial and final temperature after irradiation in samples was not over $20^{\circ} \mathrm{C}$, so we cannot say that the temperature effect stressed the strong influence of the nature of the radical with respect to their ability of monomer addition [41].

The intrinsic viscosity of a polymer, that is, the indicator of its hydrodynamic volume in solution, depends on the molecular weight, structure, chain dimension, and nature of the solvent, as well as the temperature of the medium. For two polymers having similar molecular weight, the branched polymer has a lower hydrodynamic volume compared to its linear counterpart and, thus, has lower intrinsic viscosity. Furthermore, long branches determine a higher intrinsic viscosity and vice versa $[30,42-44]$. 
In dilute solutions, the polymer chains are separate, so the polymer intrinsic viscosity depends only on the dimensions of the polymer chain and on the molecular weight [30,43,45]. Grafted polymers having high percentages of grafting efficiency will have the highest intrinsic viscosity because a higher percentage of grafting means longer polyacrylamide chains grafted onto the backbone of sodium alginate. With the increase of the absorbed dose, the intrinsic viscosity and grafting efficiency are enhanced, continuously achieving the maximum when the absorbed dose is between 1 and $1.4 \mathrm{kGy}$, and then both parameters decrease. This may be due to the accumulation of polyacrylamide molecules in close proximity to the sodium alginate backbone when the irradiation dose increases. The decrease of the intrinsic viscosity as well as of grafting efficiency after the optimization of the irradiation dose could be associated with the reduction of the active sites on the sodium alginate backbone $[30,35]$.

\subsection{Fourier Transform Infrared Spectroscopy (FTIR)}

In order to evaluate the binding of acrylamide on the sodium alginate backbone, the infrared spectra of the grafted polymers were done. By comparing the results with those obtained by other tests, a reaction mechanism was realized and the best polymers obtaining conditions were established. In Figure 3, the entire $(a, b)$ and detailed (c-f) overlapped spectra of the AMD/ALg I/ and AMD/ALg II/ samples are presented.

The band near $3400 \mathrm{~cm}^{-1}$ that corresponds to the stretching vibration of $-\mathrm{OH}$ groups of sodium alginate [25,46-49] can be seen in both AMD/ALg I (Figure 3a,c) and AMD/ALg II (Figure 3b,d) spectra. On this band, modifications are observed in absorbance for samples obtained at the same irradiation dose as a function of sodium alginate concentration. For example, the samples obtained at the lowest irradiation dose present significant increases of the absorbance, while samples obtained at the highest irradiation dose present significant decreases of the absorbance (Figure $3 c, d$ ). The variation in intensity and the shifted appearance at $3192 \mathrm{~cm}^{-1}$ (Figure 3d) and $3191 \mathrm{~cm}^{-1}$ (Figure 3c), respectively, indicates the partial participation of hydroxyl groups in the chemical reaction [25]. By doubling the sodium alginate concentration in the irradiated samples, the intensities of all samples decreased, except for the intensity of AMD/ALg II/1 sample obtained by irradiation at $1 \mathrm{kGy}$ (Figure 3d). This result indicates the formation of new bounds between $-\mathrm{NH}_{2}$ groups of polyacrylamide and carboxyl groups of alginate [49].

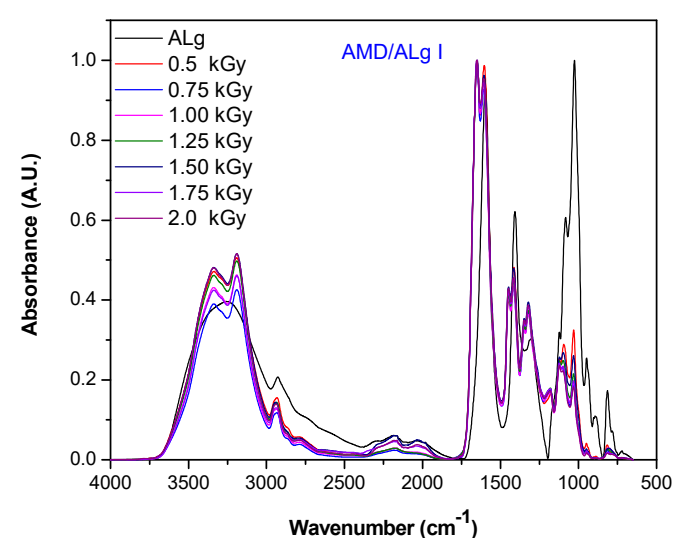

(a)

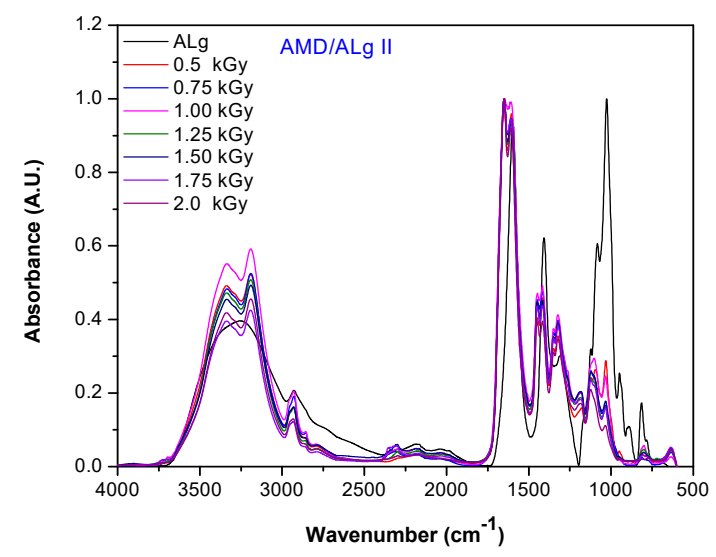

(b)

Figure 3. Cont. 


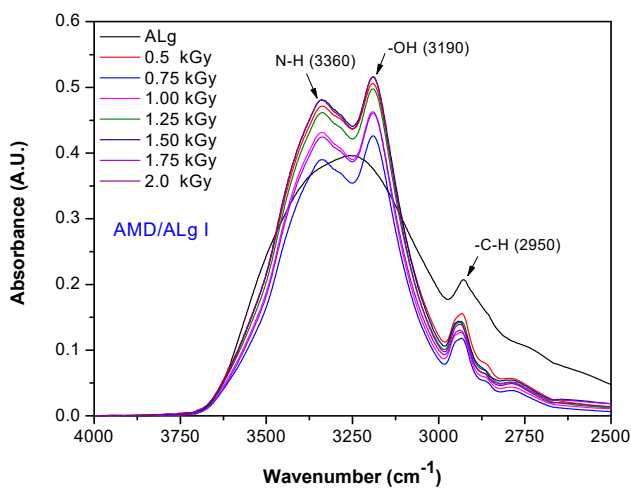

(c)

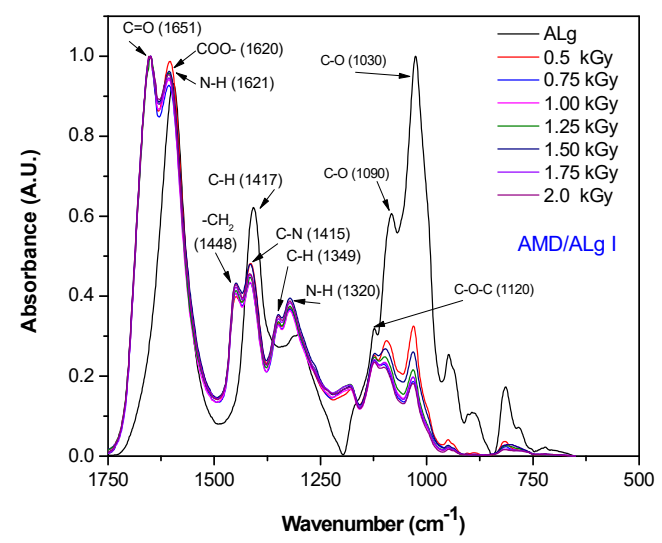

(e)

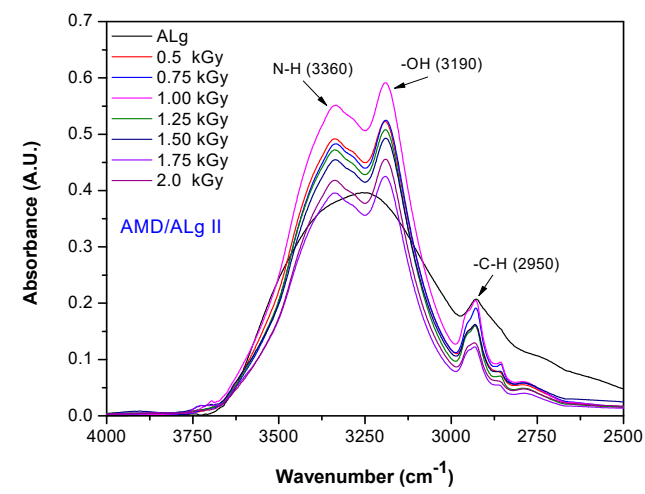

(d)

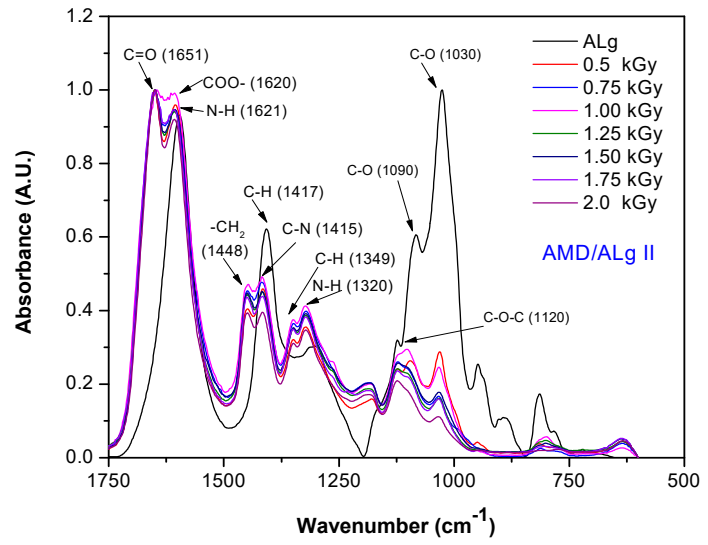

(f)

Figure 3. The FTIR spectra of AMD/ALg I (a) and AMD/ALg II (b) samples. Details of the AMD/ALg I (c), AMD/ALg II (d) spectra between 4000-2500 $\mathrm{cm}^{-1}$ and AMD/ALg I (e), AMD/ALg II (f) spectra between $1750-500 \mathrm{~cm}^{-1}$.

The sharp bands around $1620 \mathrm{~cm}^{-1}$ are attributed to the asymmetric COO-stretching. The bands at $1417 \mathrm{~cm}^{-1}$ (Figure 3e) and $1415 \mathrm{~cm}^{-1}$ (Figure 3f) and the bands around $1321 \mathrm{~cm}^{-1}$ (Figure 3e,f) correspond to the C-H deformation with secondary alcohols [49]. Finally, the bands around $1120 \mathrm{~cm}^{-1}$ (1122 $\mathrm{cm}^{-1}$ for both AMD/ALg I and AMD/ALg II), $1090 \mathrm{~cm}^{-1}\left(1094 \mathrm{~cm}^{-1}\right.$ for AMD/ALg I and 1093 $\mathrm{cm}^{-1}$ for AMD/ALg II), and $1030 \mathrm{~cm}^{-1}\left(1032 \mathrm{~cm}^{-1}\right.$ for both AMD/ALg I and AMD/ALg II) are due to the asymmetric $\mathrm{C}-\mathrm{O}-\mathrm{C}$ stretching, $\mathrm{C}-\mathrm{O}$ stretching in the $\mathrm{CH}-\mathrm{OH}$ structure and symmetric $\mathrm{C}-\mathrm{O}$ stretching in the $\mathrm{C}-\mathrm{O}-\mathrm{C}$ structure, respectively (Figure 3e,f) [49].

The bands at 3360 and $1320 \mathrm{~cm}^{-1}$ are usually attributed to the stretching vibration of $\mathrm{N}-\mathrm{H}$ [49] and we found them shifted at 3335 and $1321 \mathrm{~cm}^{-1}$, respectively. The same situation was observed in the case of the band corresponding to the $\mathrm{C}=\mathrm{O}$ stretching (around $1651 \mathrm{~cm}^{-1}$ instead of $1670 \mathrm{~cm}^{-1}$ ). The bands corresponding to the $\mathrm{N}-\mathrm{H}$ deformation for primary amine, $\mathrm{CH}_{2}$ in-plane scissoring, $\mathrm{C}-\mathrm{N}$ stretching for primary amide, C-H deformation, and NH2 in-plane rocking were found at 1621, 1448, 1417-1415, 1349, and $1122 \mathrm{~cm}^{-1}$, respectively.

By comparing Figure $3 a, c, e$ with Figure $3 b, d, f$, it is easy to observe the differences in the intensities of the same bands. In this case, the sodium alginate addition in the polymer samples of AMD/Alg II type leads to the increase of the band intensity. These results are very well correlated with the results presented in Table 3 and Figures $1 b$ and $2 a, b$, in which the intrinsic viscosity, grafting ratio, and grafting efficiency are obviously affected by doubling the sodium alginate concentration in the samples of AMD/ALg II type.

The ionizing radiation effects on monomers and polymers are the production of polymerization, cross-linking, grafting, and degradation reactions. After the interaction with monomer or polymer molecules, the electron beam, as ionizing radiation, produces, in addition to ionization, the excitation 
of the active species $[50,51]$. The energies associated with these phenomena are strongly dependent on the radiation dose. Free radicals are formed by the dissociation of molecules in the excited state or by the interaction of molecular ions. These can react through a direct connection with the polymer chains but can also initiate grafting reactions [52,53]. The formation of radicals by the decomposition of all reactants (initiator, solvent-water here and monomers) constitutes an advantage in the radiation induced reactions. In Figures 4-7, decomposition of the reactants from the system is presented: Solvent-water radiolysis (Figure 4), initiator-potassium persulfate (Figure 5), and monomers-acrylamide (Figure 6) and sodium alginate (Figure 7). Even if in radio-induced polymerization the initiation of the reaction is done by irradiation, the initiators as potassium persulfate are used in order to optimize the monomer (AMD) conversion process [54].

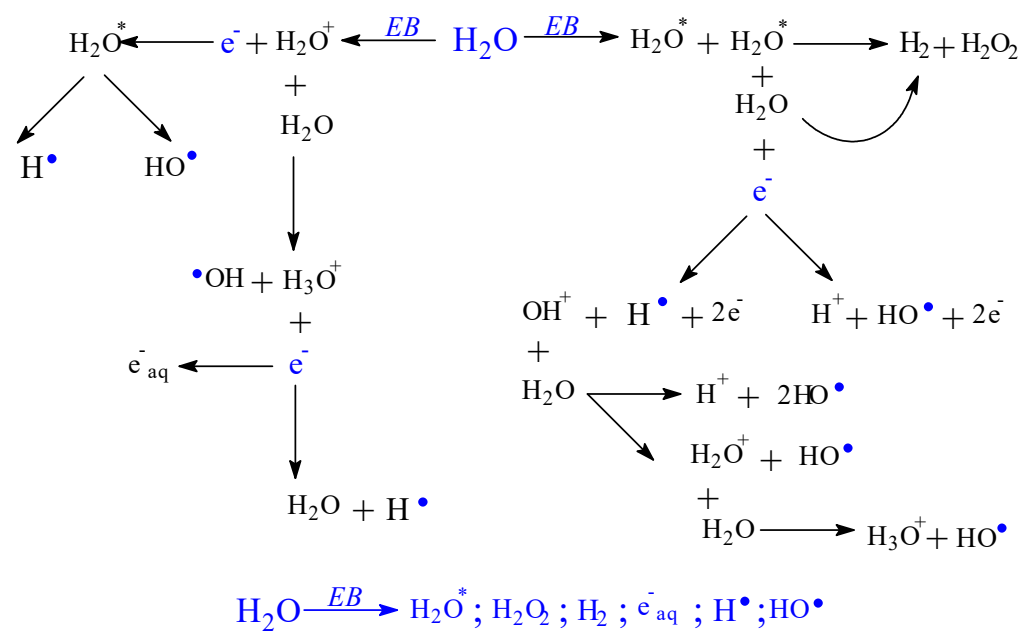

Figure 4. Possible mechanism for obtaining radicals by irradiation from water.

$$
\begin{aligned}
\mathrm{S}_{2} \mathrm{O}_{8}{ }^{2-} \stackrel{E B}{\longrightarrow} 2 \mathrm{SO}_{4}{ }^{\bullet} \\
+ \\
\mathrm{H}_{2} \mathrm{O} \longrightarrow \mathrm{HSO}_{4}{ }^{\circ}+\mathrm{HO}^{\bullet}
\end{aligned}
$$

Figure 5. Possible mechanism for obtaining radicals by irradiation from initiator, potassium persulfate.

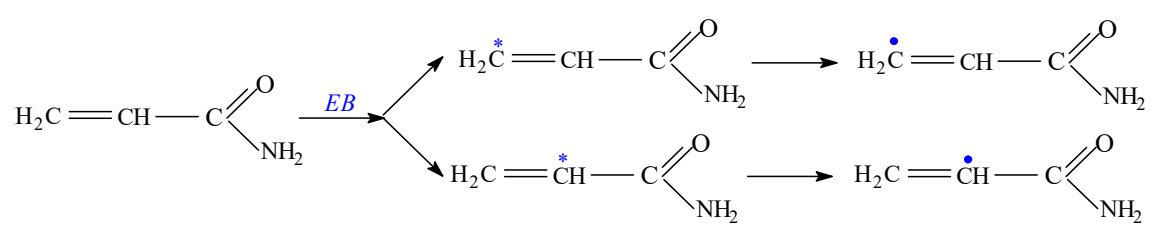

Figure 6. Possible mechanism for obtaining radicals by irradiation from acrylamide.

Chemical reactions presented in Figure 7a,b correspond to the mannuronate decomposition and are similar with the guluronate decomposition, the second group of sodium alginate.

The main role of the ionizing radiation is the achievement of the first step of the polymerization process, the initiation step, leading to the formation of free radicals. The next steps, propagation, completion, and the chain transfer, take place almost identically as in classic polymerization/grafting processes. Through the sodium alginate irradiation, radicals having unpaired electrons are formed, mainly in positions 1, 2, 3, 4, and 5 of the pyranose ring, as is shown in Figure 7. These radicals should originate from hydrogen abstraction from positions mentioned above and from the $\mathrm{OH}$ group [55]. The radicals formed from positions 2 and 3 of the pyranose ring may form, in their turn, other radicals by loss of a water molecule. The radical species can be also formed by cleavage of a glycosidic bond, from $\alpha$ and $\beta$-fragmentation of an oxygen-centered radical resulted from the cleavage of a glycosidic bond [55], and by chain scission, as shown in Figure 7c. As seen in Figure 7a-c, free radicals are formed 
after $\mathrm{C}-\mathrm{H}, \mathrm{C}-\mathrm{O}$, and $\mathrm{C}-\mathrm{C}$ bond cleavages by hydrogen abstraction, chain scission, and cycle opening. Through acrylamide addition, no unsaturated bond remains when a radical is created.
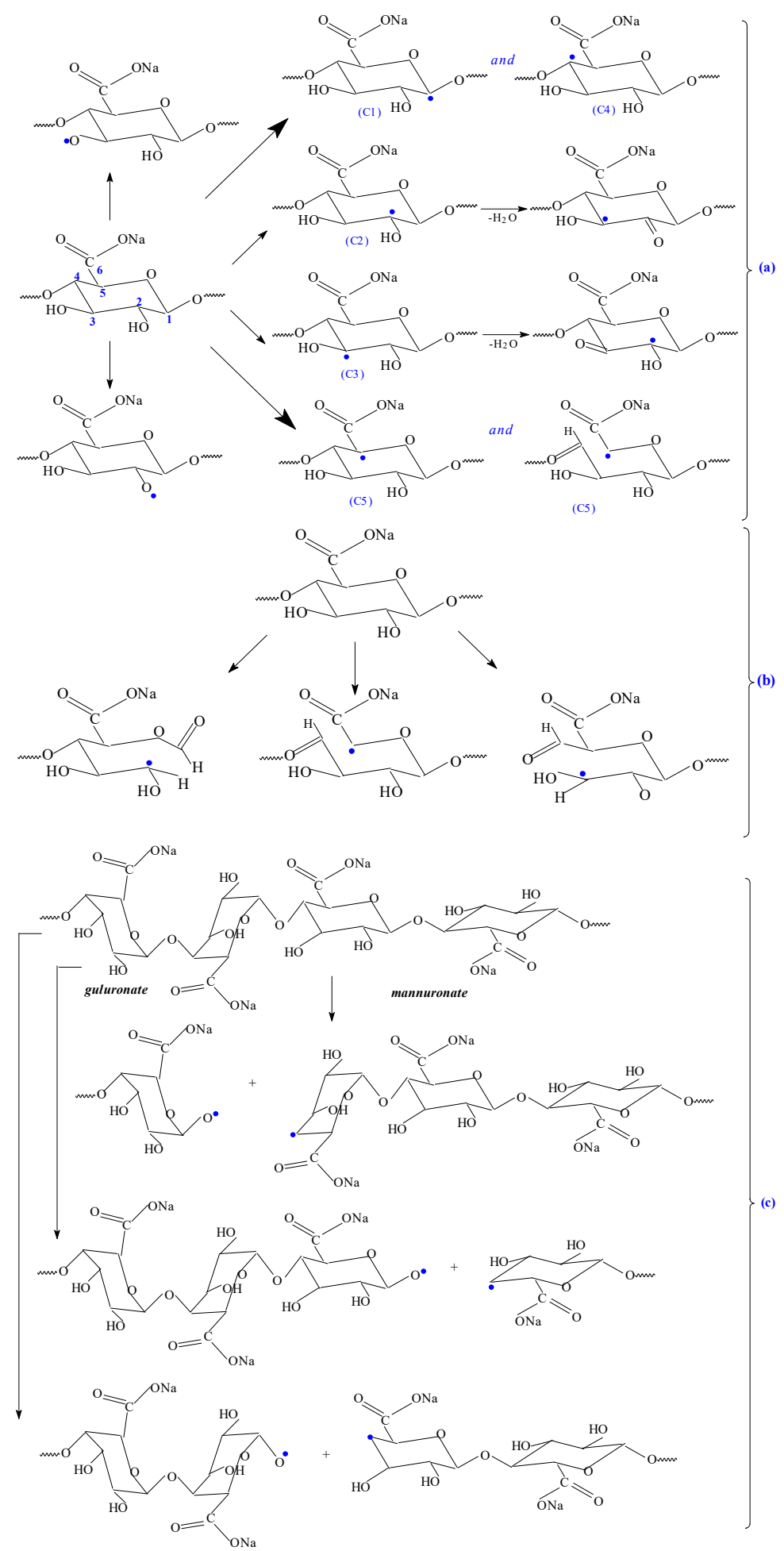

Figure 7. Possible mechanism for obtaining radicals by irradiation from sodium alginate.

In order to correlate the results obtained by the FTIR technique with those obtained after the evaluation of the flocculation performance, based on other results presented in the literature $[25,47,56]$, a possible reaction mechanism is proposed (Figure 8) to highlight how the PAM is bound to the sodium 
alginate structure, and that the sodium alginate is responsible for the performances of SALg-g-PAM type as flocculant.

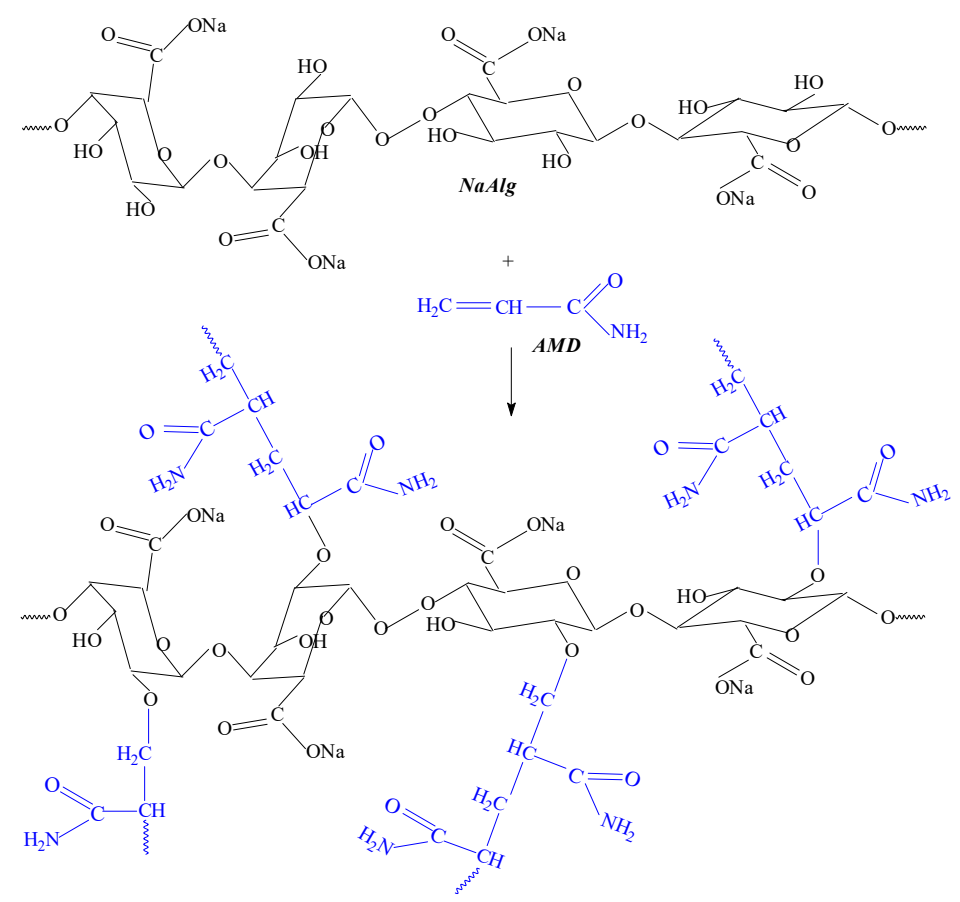

Figure 8. Possible mechanism of acrylamide grafting on sodium alginate backbone.

Thus, the FTIR spectrum of polyacrylamide displays principally large bands due to the asymmetric and symmetric $\mathrm{NH}_{2}$ stretching vibrations in the regions of $3350-3330$ and $3200-3190 \mathrm{~cm}^{-1}$ and due to asymmetric and symmetric $\mathrm{CH}_{2}$ stretching vibrations in the region of $2930-2900 \mathrm{~cm}^{-1}$, respectively. Additionally, the methylene group vibrations were used to evaluate the extension of polymerization of acrylamide as it is presented in Figure 8. The appearance of bands in the regions 1654-1645, 1620-1605, and $1450-1415 \mathrm{~cm}^{-1}$ can be attributed to the stretching of the $\mathrm{C}=\mathrm{O}$ group (amide I), $\mathrm{NH}_{2}$ bending (amide II), and C-N stretching vibrations (amide III), respectively.

The sodium alginate spectrum exhibits mainly bands due to: The $\mathrm{Na}-\mathrm{O}$ stretching at $815-800 \mathrm{~cm}^{-1}$, the stretching frequency of the $-\mathrm{OH}$ group at $3400-3000 \mathrm{~cm}^{-1}$, the COO- group at $1610-1605 \mathrm{~cm}^{-1}$ and $1417-1415 \mathrm{~cm}^{-1}$, and the $\mathrm{C}-\mathrm{O}$ group [25,47].

In the sodium alginate- $g$-acrylamide spectrum, all the absorption bands that were mentioned above are shifted, indicating that the interaction between the functional groups of sodium alginate and polyacrylamide occurs. The bands at 2942-2933, 1608-1605, 1418-1414, and 1034-1031 $\mathrm{cm}^{-1}$ presented in the mentioned spectra indicate the stretching vibrations of aliphatic $\mathrm{C}-\mathrm{H}, \mathrm{COO}-$ (asymmetric), COO- (symmetric), and C-O [56]. Moreover, the band located at $3192-3190 \mathrm{~cm}^{-1}$ that is due to the $\mathrm{OH}$ stretching vibration [25] shows variations in intensity depending on the irradiation dose, which indicates the participation of hydroxyl groups in the chemical reaction, as shown in Figure 8. More than that, some additional bands in the copolymer spectrum are at 1651-1648, 1614-1605, and 1415-1414 $\mathrm{cm}^{-1}$ which correspond to the carbonyl amide, $\mathrm{N}-\mathrm{H}$, and $\mathrm{C}-\mathrm{N}$ stretching vibrations $[25,47]$. All these bands have confirmed the grafting of polyacrylamide on the sodium alginate backbone, as in Figure 8.

\subsection{Flocculation Study Results}

Grafted polymers characterized as above were used in flocculation studies that were carried out on kaolin suspension at room temperature of $25^{\circ} \mathrm{C}$. The influence of kaolin concentration $(0.05,0.1$, and 
$0.2 \mathrm{wt} \%$ ), polymer concentration ( 0.5 to $10 \mathrm{ppm})$, and rotation speed (60 and $90 \mathrm{rpm}$ ) on flocculation efficacy in terms of transmittance against distilled water were studied.

For the first experiment set, in the Jar test glass bakers filled with $500 \mathrm{~mL}$ kaolin suspension of 0.1 and $0.2 \mathrm{wt} \%$ were added polyelectrolytes of AMD/ALg I and AMD/ALg II types in different concentrations between 0.5 and $10 \mathrm{ppm}$. Samples were stirred first at $60 \mathrm{rpm}$ for $15 \mathrm{~min}$, then left to rest for another $15 \mathrm{~min}$ before sampling for analysis from the top layer clear supernatant. The results are presented in Figure 9.

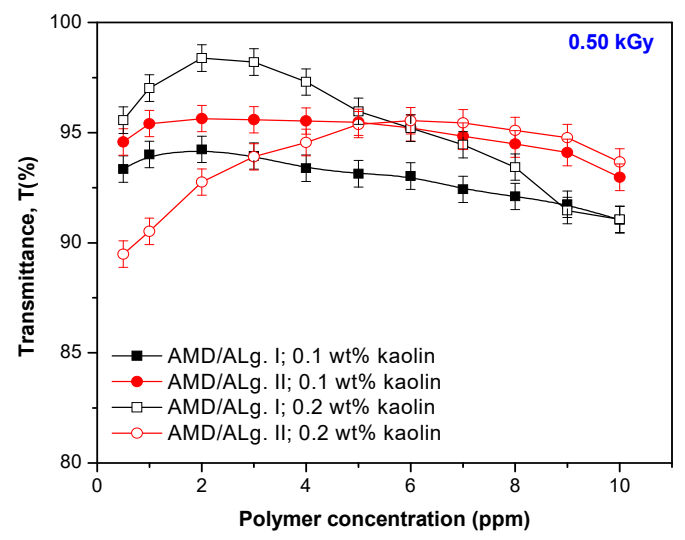

(a)

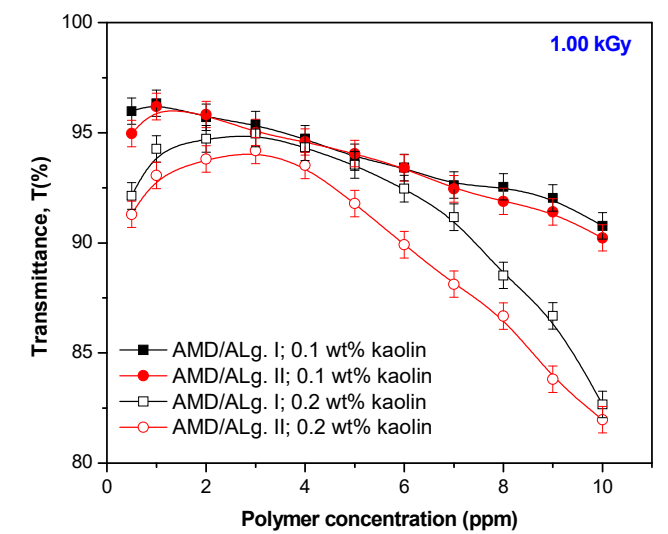

(c)

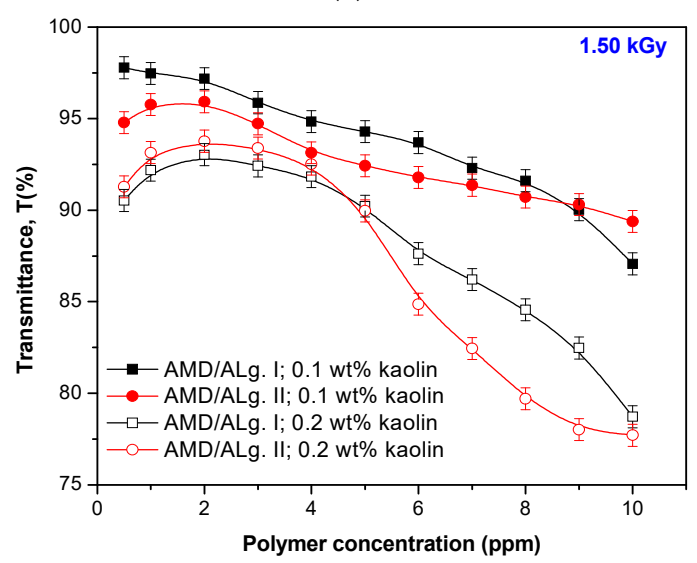

(e)

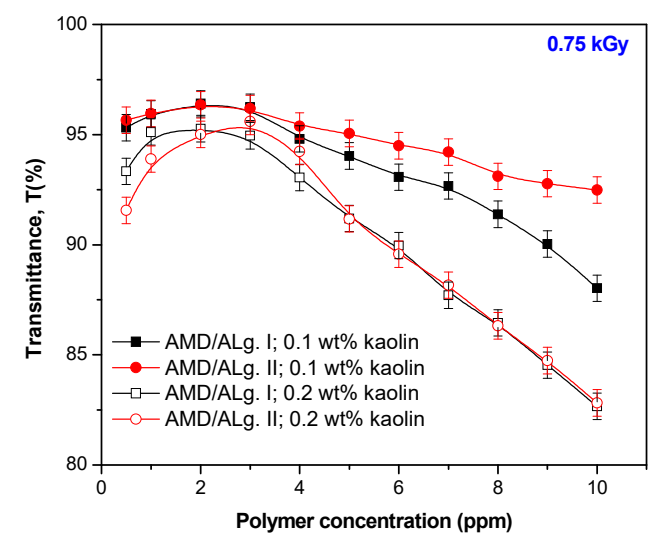

(b)

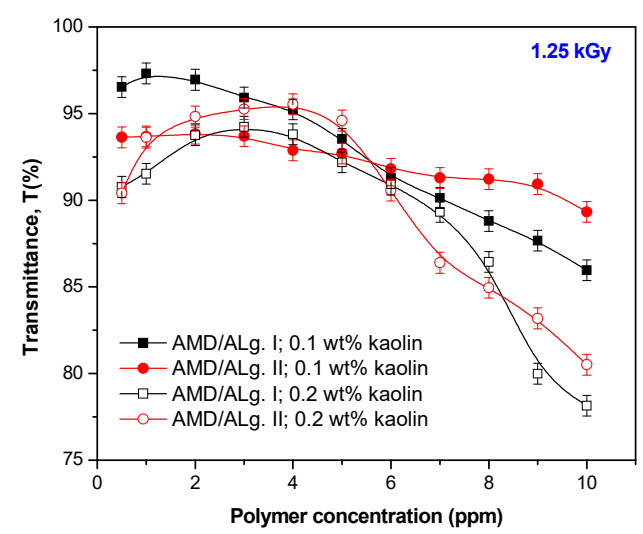

(d)

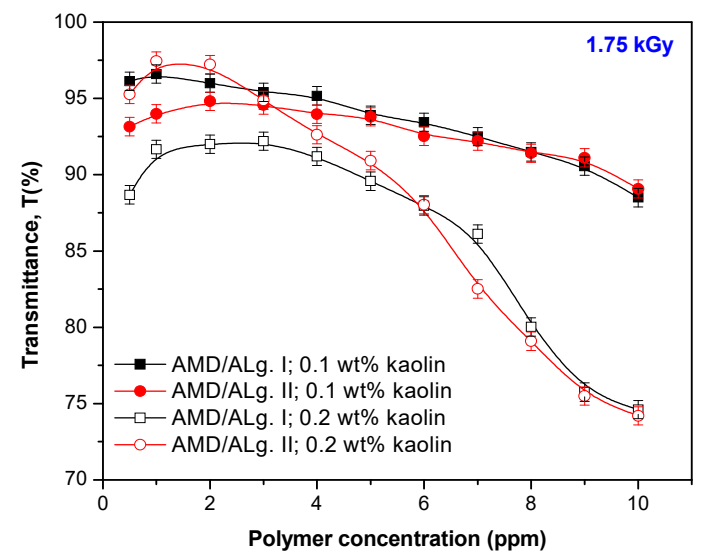

(f)

Figure 9. Cont. 


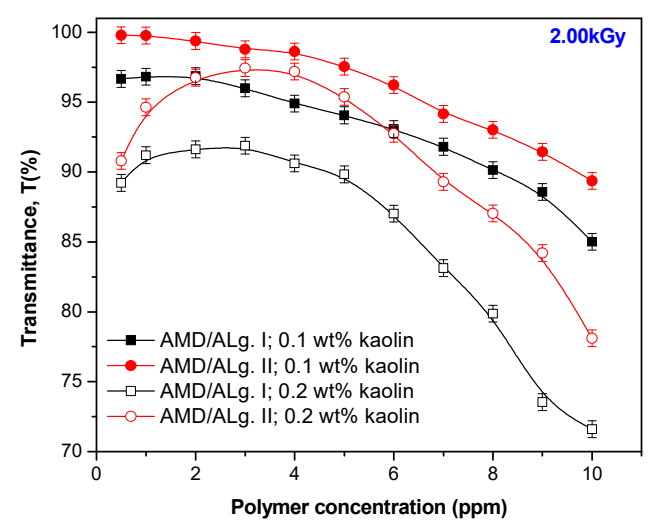

(g)

Figure 9. The influence of the polymer type and kaolin concentration on the samples transmittance: AMD/ALg I and II obtained at $0.5 \mathrm{kGy}(\mathbf{a}), 0.75 \mathrm{kGy}(\mathbf{b}), 1 \mathrm{kGy}(\mathbf{c}), 1.25 \mathrm{kGy}$ (d), $1.5 \mathrm{kGy}(\mathbf{e}), 1.75 \mathrm{kGy}$ (f), and $2 \mathrm{kGy}(\mathrm{g})$.

As seen in Figure 9, the increase of the polymer concentration over 4 ppm leads to the obtainment of transmittances that are increasingly small, irrespective of the irradiation dose at which the polymers were obtained or of the concentration of the kaolin suspension. In the range of polymer concentration from 1 to $4 \mathrm{ppm}$, transmittances over 90\% were obtained for both 0.1 and $0.2 \mathrm{wt} \%$ kaolin suspensions. In the experiments that were made on the kaolin suspension of $0.1 \mathrm{wt} \%$, the influence of the sodium alginate concentration in the polymer sample was as follows:

1. Using polymers of AMD/ALg I type in concentration of $1 \mathrm{ppm}$, transmittances over $96 \%$ were obtained (Figure 9b-g), except in the case of AMD/ALg I/0.5;

2. Using polymers of AMD/ALg II type in concentrations of 0.5 and $1 \mathrm{ppm}$, higher net transmittances were obtained in the case of AMD/ALg II/0.5 (over 98\%, Figure 9a) and AMD/ALg II/2 (100\%, Figure 9g);

3. Considering as being of interest the concentration range between 0.5 and $4 \mathrm{ppm}$, it can be observed that even if the polymers of AMD/ALg II types physicochemical properties are inferior to those of AMD/ALg I types, especially in terms of intrinsic viscosity/molecular weight, the best flocculation results were obtained in the case of their use (AMD/ALg II/2 having intrinsic viscosity of $1.283 \mathrm{dl} / \mathrm{g}$ versus AMD/ALg I/1 having intrinsic viscosity of $2.081 \mathrm{dl} / \mathrm{g}$ );

In the experiments that were made on the kaolin suspension of $0.2 \mathrm{wt} \%$, the influence of the sodium alginate concentration in the polymer sample was as follows:

1. Irrespective of the polymer type used, the maximum transmittance did not reach $100 \%$. However, there were some cases in which over 97\% was obtained: AMD/ALg I/0.5, AMD/ALg II/1.75 and AMD/ALg II/ 2 for polymer concentrations of 2 ppm (Figure 9a), 1 ppm (Figure 9f), and 3 ppm (Figure 9g);

2. Except in the cases of AMD/ALg I/0.5, AMD/ALg I/0.75, and AMD/ALg I/1, the polymers of AMD/ALg II types were more efficient than those of AMD/ALg I types. Thus, I can be said that for more concentrated kaolin suspensions, high sodium alginate concentrations are needed, and for AMD/ALg II polymer types, higher irradiation doses are necessary;

3. In order to obtain similar results, polymers of AMD/ALg I type have to be used in lower concentrations than polymers of AMD/ALg II type.

For the second experiment set, the polymers of AMD/ALg II type, having lower intrinsic viscosity, grafting degree, and grafting efficiency, were deliberately chosen. The experiments were done almost in the same way, the only differences consisting of the kaolin suspension concentration $(0.05,0.1$ and $0.2 \mathrm{wt} \%$ ) and rotation speed (90 rpm). The results are presented in Figure 10. 


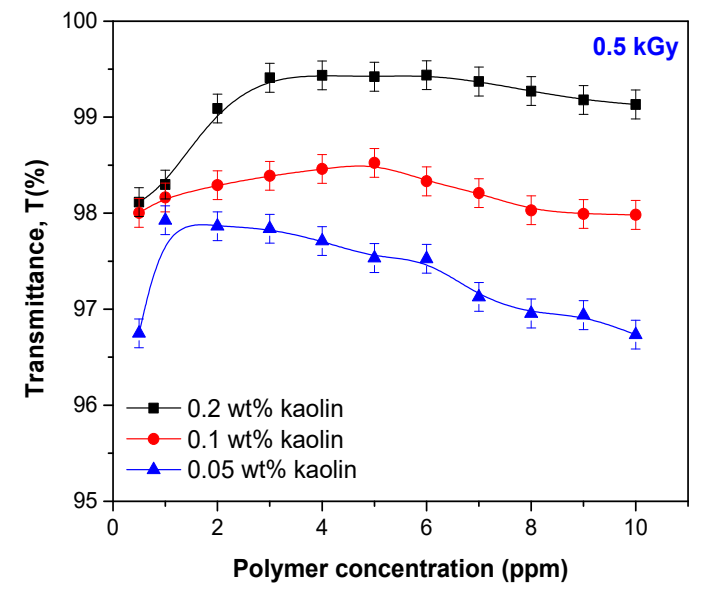

(a)

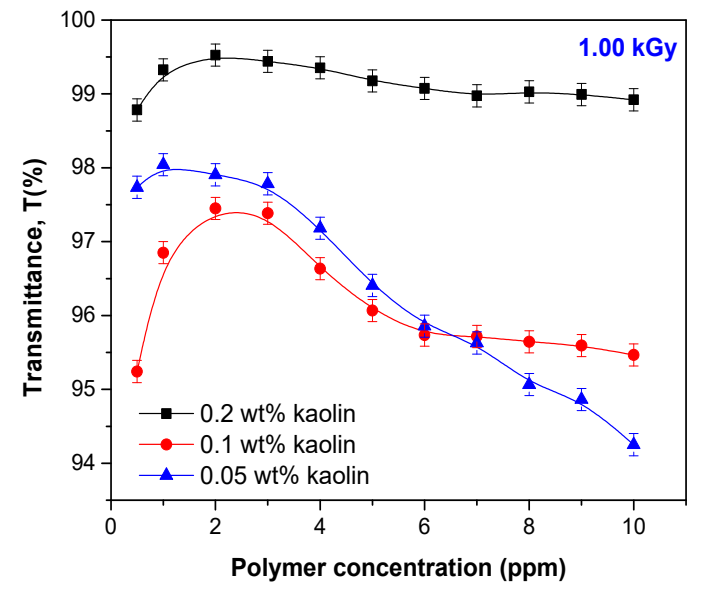

(c)

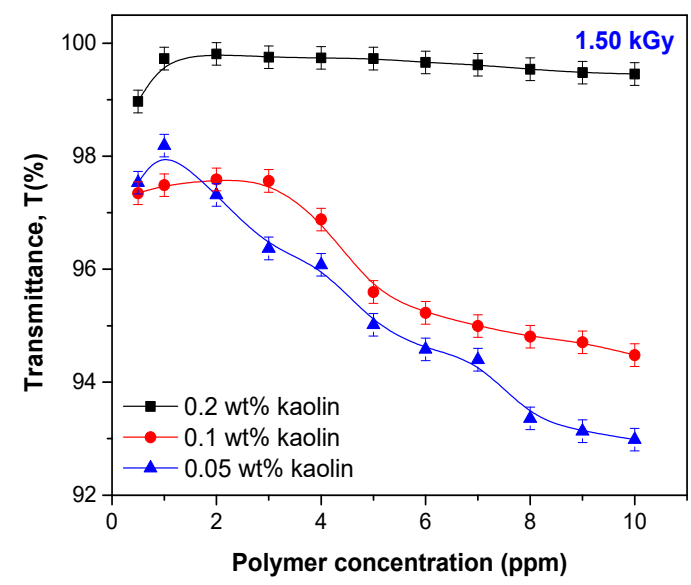

(e)

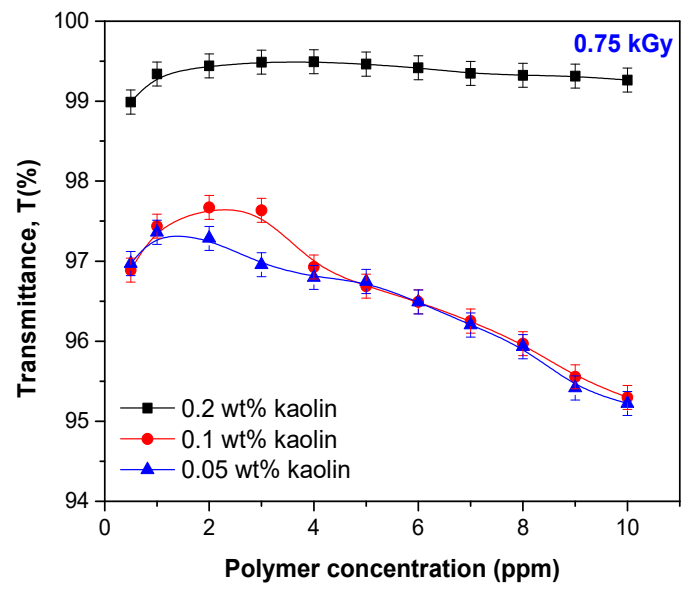

(b)

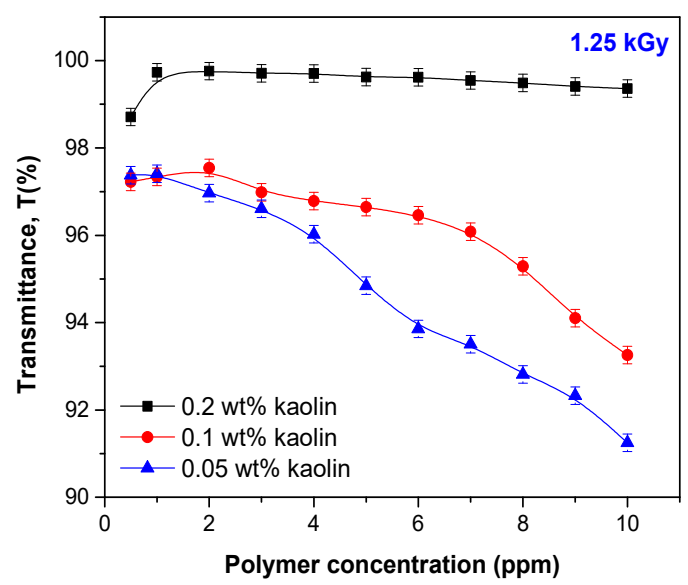

(d)

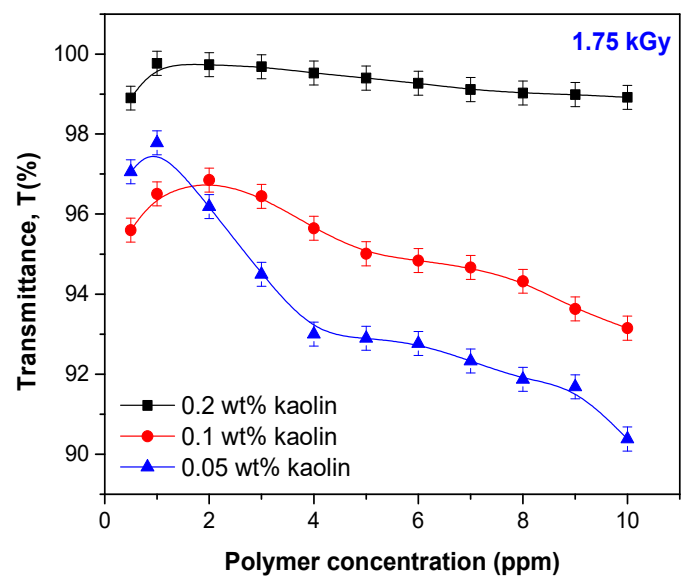

(f)

Figure 10. Cont. 


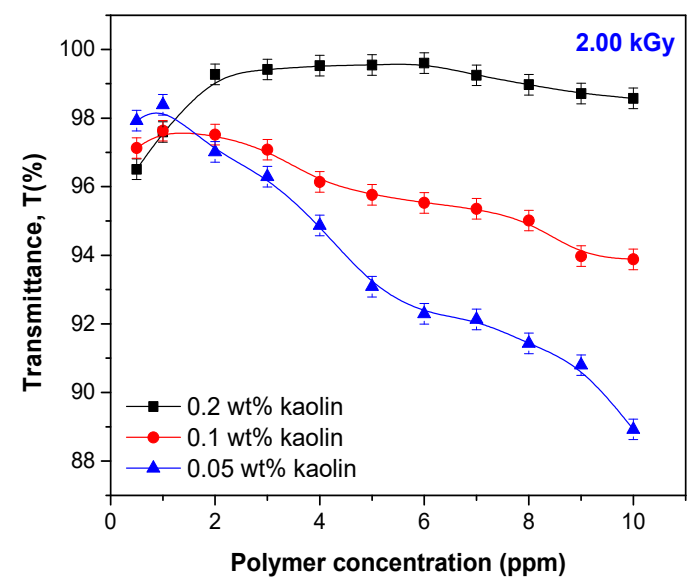

(g)

Figure 10. The influence of the kaolin concentration on the samples transmittance: AMD/ALg II obtained at $0.5 \mathrm{kGy}(\mathbf{a}), 0.75 \mathrm{kGy}(\mathbf{b}), 1 \mathrm{kGy}(\mathbf{c}), 1.25 \mathrm{kGy}(\mathbf{d}), 1.5 \mathrm{kGy}(\mathbf{e}), 1.75 \mathrm{kGy}(\mathbf{f})$, and $2 \mathrm{kGy}(\mathrm{g})$.

As seen in Figure 10, as the kaolin suspension is more concentrated, the polymers having higher sodium alginate content obtained at the irradiation dose between 0.75 and $1.75 \mathrm{kGy}$ are more efficient. For the kaolin suspension of $0.2 \mathrm{wt} \%$, the polymer concentration of $1 \mathrm{ppm}$ is enough to obtain transmittances over $99 \%$. For the kaolin suspensions of 0.05 and $1 \mathrm{wt} \%$, the same tendency as in the first experiments set appeared. Only small polymer concentrations (around $1 \mathrm{ppm}$ for $0.05 \mathrm{wt}$ $\%$ and $2 \mathrm{ppm}$ for $1 \mathrm{wt} \%$, except for AMD/ALgII/0.5 and AMD/ALgII/1.5) led to the obtainment of transmittances up to $98 \%$. By increasing the polymer concentration, the flocculation results were depreciated for both the 0.05 and $1 \mathrm{wt} \%$ kaolin suspension but keeping the tendency for the worst results as the kaolin concentration decreases.

Many authors developed bridging theories that provide the abilities of polymers having high molecular weights [57-59] and grafting ratios [60,61] to destabilize colloidal suspensions. Destabilization by bridging occurs when segments of a polymer chain adsorb one or more particles, thereby linking the particle together. When a polymer molecule comes into contact with a colloidal particle, some of the reactive groups of the polymer adsorb at the particle surface, leaving other portions of the molecule extending in the solution. The polymer will adsorb on the surface in a series of loops and trails. If a second particle with some vacant adsorption sites contacts the extended loops and trails, attachment can occur. A particle-polymer-particle aggregate is formed, in which the polymer serves as a bridge $[58,60]$.

Because our flocculation experiments were carried out in neutral conditions (the $\mathrm{pH}$ of kaolin suspension was of 7) and based on experimental facts regarding the aspect of the formed aggregates, we consider that the flocculation mechanisms that occurred in our experiments were based on bridging, first because this mechanism is dominant in neutral and alkaline conditions [58,60], and second, because of the compact aspect of the flocs.

\subsection{Metal Ion Removal Study Results}

Metal ion removal experiments were done at room temperature in aqueous solutions containing concentrations of $500 \mathrm{mg} / \mathrm{L} \mathrm{Cu}^{2+}$ and $\mathrm{Cr}^{6+}$ ions. High initial concentrations usually provide the driving forces necessary to overcome mass transfer resistance of a metal ion between the aqueous solution and the solid and increase the metal uptake. In addition, a high initial concentration increases the number of collisions between metal ions and sorbent, which enhances the sorption process $[23,62,63]$.

The flocculant amount of $1 \mathrm{~g}$ was used in experiments. Graft copolymer samples were immersed for $24 \mathrm{~h}$ at room temperature of $25{ }^{\circ} \mathrm{C}$ in $20 \mathrm{~mL}$ solution of metal ions having a neutral $\mathrm{pH}$ of 7. After treatment, samples of metallic solutions were analyzed using a Cary Bio-100 UV-VIS Spectrophotometer in order to determine the residual concentration. The influence of the grafting 
conditions (irradiation dose) and sodium alginate concentration on removal efficiency and absorption capacity after $24 \mathrm{~h}$ was studied. The results are presented in Figures 11 and 12.

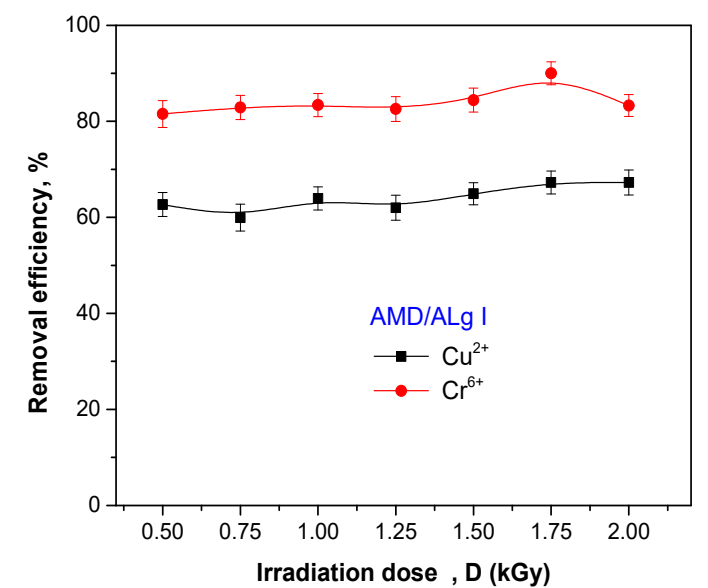

(a)

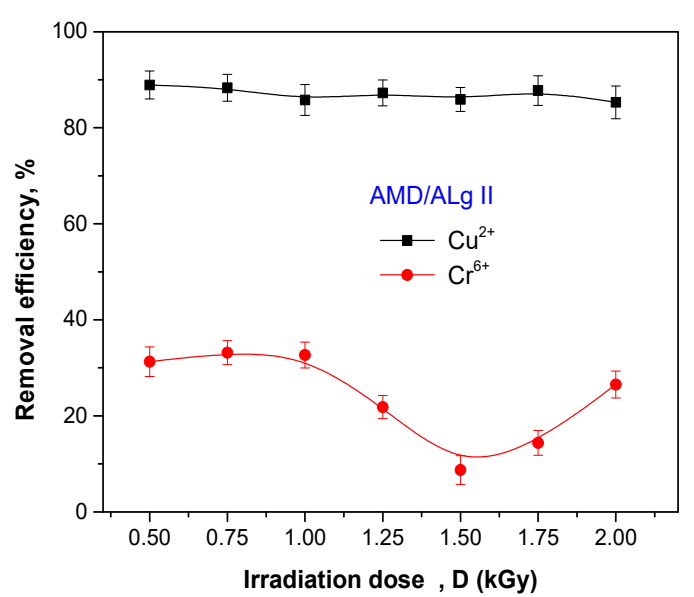

(c)

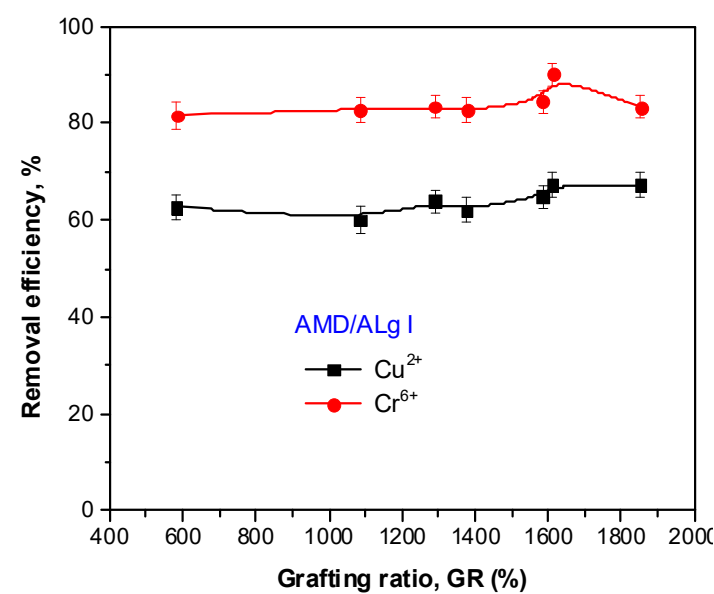

(b)

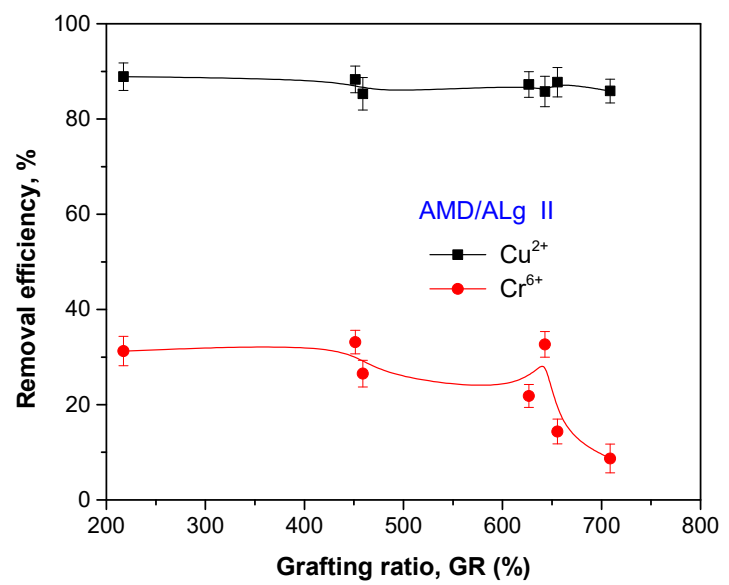

(d)

Figure 11. The influence of irradiation dose, grafting ratio, and sodium alginate concentration on $\mathrm{Cu}^{2+}$ and $\mathrm{Cr}^{6+}$ ion removal efficiency. (a) removal efficiency versus irradiation dose for AMD/ALg I samples; (b) removal efficiency versus grafting ratio for AMD/ALg I samples; (c) removal efficiency versus irradiation dose for AMD/ALg II samples; (d) removal efficiency versus grafting ratio for AMD/ALg II samples.

In Figure 11, it can be seen that irrespective of irradiation dose and grafting ratio, polyelectrolyte samples of AMD/ALg I type were over $80 \%$ efficient in $\mathrm{Cr}^{6+}$ removal and over $60 \%$ in $\mathrm{Cu}^{2+}$ removal, while samples of AMD/ALg II type were near 90\% efficient in $\mathrm{Cu}^{2+}$ removal and between 10 and 30\% efficient in $\mathrm{Cr}^{6+}$ removal. In the case of the AMD/ALg II type, the increase of the irradiation dose and grafting ratio led to the obtainment of polymers that are less efficient in $\mathrm{Cr}^{6+}$ ion removal.

In Figure 12a,b, it can be seen that after $24 \mathrm{~h}$, the absorption capacities of both $\mathrm{Cr}^{6+}$ and $\mathrm{Cu}^{2+}$ ions calculated for AMD/ALg I polymer type are dependent on the irradiation dose and grafting ratio. The absorption capacity of $\mathrm{Cu}^{2+}$ ions was around $15 \mathrm{mg} / \mathrm{g}$ irrespective of irradiation dose up to $1.5 \mathrm{kGy}$ and grafting ratio up to $1600 \%$. The increase of the irradiation dose with $0.5 \mathrm{kGy}$ up to $2 \mathrm{kGy}$ is reflected in the increase of the grafting ratio with $400 \%$, which led to an improvement in the absorption capacity of $\mathrm{Cu}^{2+}$ ions with almost $30 \%$. 


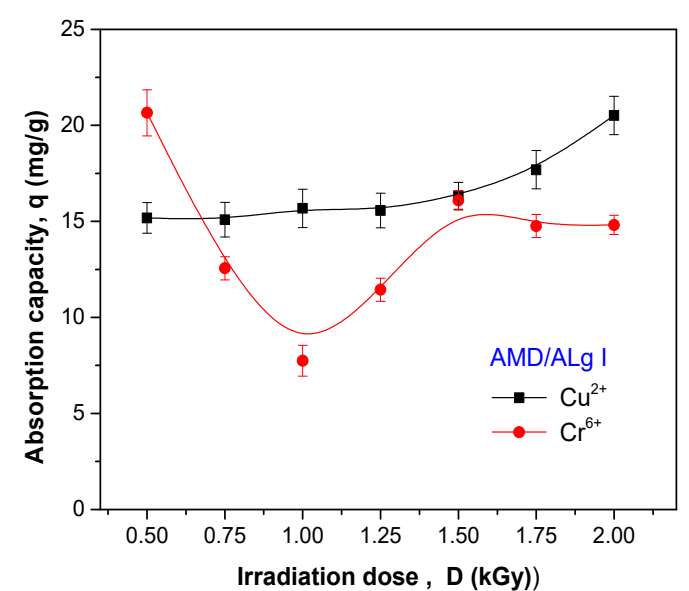

(a)

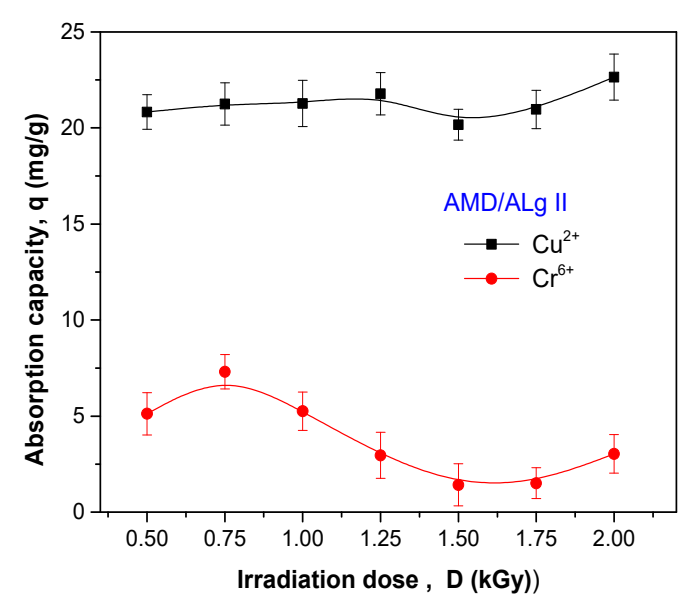

(c)

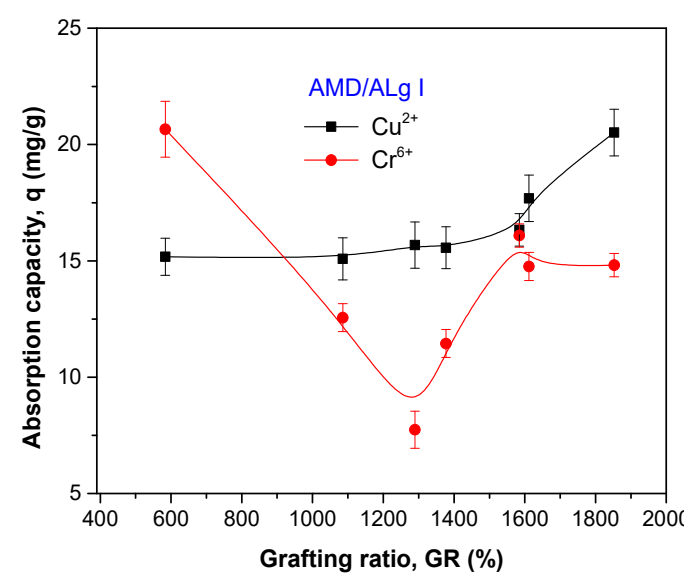

(b)

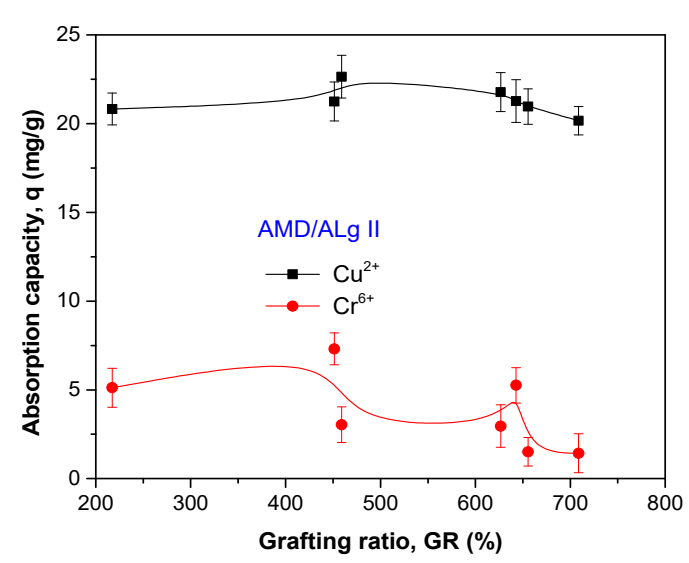

(d)

Figure 12. The influence of irradiation dose, grafting ratio, and sodium alginate concentration on equilibrium absorption capacity. (a) absorption capacity versus irradiation dose for AMD/ALg I samples; (b) absorption capacity versus grafting ratio for AMD/ALg I samples; (c) absorption capacity versus irradiation dose for AMD/ALg II samples; (d) absorption capacity versus grafting ratio for AMD/ALg II samples.

As seen in Figure $12 \mathrm{c}, \mathrm{d}$, the absorption capacity of $\mathrm{Cu}^{2+}$ ions presented only small variations around $20 \mathrm{mg} / \mathrm{g}$ when the AMD/ALg II polymer type was used, the highest value being obtained for the grafting ratio of $500 \%$. By comparison, the absorption capacity of $\mathrm{Cr}^{6+}$ ions is modest, just passing over $5 \mathrm{mg} / \mathrm{g}$ for a grafting ratio of $400 \%$.

The results suggest that polyelectrolytes of AMD/ALg I type having high grafting ratios (between $600 \%$ and $1900 \%$ ) are efficient in $\mathrm{Cr}^{6+}$ ion removal, while the polyelectrolytes of AMD/ALg II type having small grafting ratios (between $200 \%$ and $700 \%$ ) are efficient in $\mathrm{Cu}^{2+}$ ion removal. The results are comparable to those reported in the literature [23,64].

The experiments for heavy metal ion $\left(\mathrm{Cu}^{2+}\right.$ and $\left.\mathrm{Cr}^{6+}\right)$ removal using exclusive sodium alginate were performed by introducing 0.1 grams (experiment $a$ ) and 0.2 grams (experiment $b$ ) in $20 \mathrm{~mL}$ of $500 \mathrm{mg} / \mathrm{L} \mathrm{Cu}^{2+}$ and $\mathrm{Cr}^{6+}$ ions. The sodium alginate in the chrome solution was totally dissolved; thus, the spectrophotometric measurements could not be done. The sodium alginate in the cooper solution did not dissolve after $24 \mathrm{~h}$ and spectrophotometric measurements were performed. The absorption capacities were of $3.62 \mathrm{mg}$ of cooper per gram of sodium alginate in experiment $a$ and of $30.5 \mathrm{mg}$ of cooper per gram of sodium alginate in experiment $b$. These results could not be compared with those presented in Figures 11 and 12, where the results were reported for every gram of grafted polymer. 
Even if the copolymers of AMD/Alg I and AMD/Alg II type contain, in each gram, 0.01 grams and 0.02 grams respectively of sodium alginate, they were more efficient in cooper removal than the alginate alone.

Even if, generally, the initial heavy metal ions concentration is very low in most wastewaters [64], it is necessary to continue the development of new types of polymeric materials applicable for wastewaters coming from very high polluting industries with heavy metals (textile, leather, metallurgical, etc.). Hence, the results obtained in our experiments are important because they have shown high heavy metal ion removal capacities using low flocculant concentration.

Additionally, in the literature, satisfactory results are presented regarding heavy metal removal using superabsorbent hydrogels, but it is hard for them to be applied to existing technological systems. Most water purification systems use the currently flocculation method with polyelectrolytes, like a studied product.

\section{Conclusions}

Two types of sodium alginate-g-acrylamide polyelectrolytes (AMD/ALg I and AMD/ALg II containing $1 \%$ and $2 \%$ sodium alginate, respectively) were obtained by electron beam irradiation in the range of 0.5 to $2 \mathrm{kGy}$. The grafting of acrylamide onto the sodium alginate backbone was evaluated and highlighted by physical, chemical, and structural analysis. The differences of $1500 \%$ between the grafting ratios and of $30 \%$ between the grafting efficiencies of the grafted products wave showed that the irradiation dose over $1.5 \mathrm{kGy}$ became critical when the sodium alginate concentration was doubled. The grafted products were used in flocculation and heavy metal ion removal studies. The polyelectrolyte type, concentration, rotation speed, and contact time were found to be of a notable importance on flocculation efficacy. Even the grafting ratio of AMD/ALg II type was only up to $500 \%$, the polyelectrolytes of this type were more efficient than the AMD/ALg I type used in the same concentration, as the kaolin concentration increased. However, by decreasing the polyelectrolyte concentration at $1 \mathrm{ppm}$ and increasing the rotation speed to $90 \mathrm{rpm}$, the AMD/ALg I type became more efficient and transmittances against distilled water near $100 \%$ were obtained. The heavy metal ion removal studies show that the polyelectrolytes of AMD/ALg I type are more efficient in $\mathrm{Cr}^{6+}$ ion removal, while the polyelectrolytes of AMD/ALg II type in $\mathrm{Cu}^{2+}$ ion removal. Both the removal efficiency and absorption capacity results suggest that the irradiation dose is critical for obtaining efficient polyelectrolytes for $\mathrm{Cr}^{6+}$ ion removal.

Author Contributions: The authors' contribution was as follows: Conceptualization and methodology, G.C. and E.M.; investigations, E.M., G.C. and D.I.; writing-original draft preparation, G.C.; writing-review and editing, D.I.

Funding: This research was funded by Romanian Ministry of National Education and Scientific Research through NUCLEU Program, grant numbers PN 18.13.01.01./2018 and PN 18.13.01.02./2018.

Conflicts of Interest: The authors declare no conflict of interest.

\section{References}

1. Craciun, G.; Manaila, E.; Martin, D.; Ighigeanu, D. Polyelectrolytes obtained by ionizing and non-ionizing radiation. In Practical Aspects and Applications of Electron Beam Irradiation, 1st ed.; Nemtanu, M.R., Brasoveanu, M., Eds.; Transworld Research Network: Kerala, India, 2011; pp. 167-179. ISBN 978-81-7895-541-4.

2. CEW. Available online: http:/ /infohouse.p2ric.org/ref/10/09949.htm (accessed on 30 October 2018).

3. Bolto, B.; Gregory, J. Organic polyelectrolytes in water treatment. Water Res. 2007, 41, 2301-2324. [CrossRef] [PubMed]

4. Kawamura, S. Considerations on improving flocculation. J. Am. Water Works Assoc. 1976, 68, 328-336. [CrossRef]

5. Rout, D.; Verma, R.; Agarwal, S.K. Polyelectrolyte treatment-An approach for water quality improvement. Water Sci. Technol. 1999, 40, 137-141. [CrossRef] 
6. Nozaic, D.J.; Freese, S.D.; Thompson, P. Long term experience in the use of polymeric coagulants at Umgeni Water. Water Sci. Technol. Water Supply 2001, 1, 43-50. [CrossRef]

7. Leu, R.J.; Ghosh, M.M. Poly-electrolyte characteristics and flocculation. J. Am. Water Works Assoc. 1988, 80, 159-167. Available online: https:/ / www.jstor.org/stable/41292143 (accessed on 30 October 2018). [CrossRef]

8. Boggs, S.; Livermore, D.G.; Seitz, M.G. Humic macromolecules in natural-waters. J. Macromol. Sci. Rev. Macromol. Chem. Phys. 1985, C25, 599-657. [CrossRef]

9. Brostow, W.; Lobland, H.E.H.; Pal, S.; Singh, R.P. Polymeric flocculants for wastewater and industrial effluent treatment. J. Mater. Educ. 2009, 31, 157-166. Available online: https://pdfs.semanticscholar.org/e5de/ a2d4df7216dcd6e148de22b8a630aa1e4af8.pdf (accessed on 30 October 2018).

10. Sahu, O.P.; Chaudhari, P.K. Review on Chemical treatment of Industrial Waste Water. J. Appl. Sci. Environ. Manag. 2013, 17, 241-257. Available online: http:/ /www.bioline.org.br/pdf?ja13028 (accessed on 30 October 2018). [CrossRef]

11. Singh, R.P.; Tripathy, T.; Karmakar, G.P.; Rath, S.K.; Karmakar, N.C.; Pandey, S.R.; Kannan, K.; Jain, S.K.; Lan, N.T. Novel biodegradable flocculants based on polysaccharides. Curr. Sci. India 2000, 78, 798-803. Available online: http:/ / www.iisc.ernet.in/currsci/apr102000/researchaccount.pdf (accessed on 30 October 2018).

12. Swanson, C.L.; Shogren, R.L.; Fanta, G.F.; Imam, S.H. Starch-plastic materials—Preparation, physical properties, and biodegradability (a review of recent USDA research). J. Environ. Polym. Degrad. 1993, 1, 155-166. Available online: https:/ /link.springer.com/article/10.1007/BF01418208 (accessed on 30 October 2018). [CrossRef]

13. Singh, R.P. Advanced Turbulent Drag Reducing and Flocculating Materials Based on Polysaccharides. In Polymers and Other Advanced Materials: Emerging Technologies and Business Opportunities, 1st ed.; Prasad, P.N., Mark, E., Fai, T.J., Eds.; Plenum Press: New York, NY, USA, 1995; pp. 227-249. ISBN 978-1-4899-0504-8.

14. Kumar, D.; Pandey, J.; Raj, V.; Kumar, P. A Review on the Modification of Polysaccharide through Graft Copolymerization for Various Potential Applications. Open Med. Chem. J. 2017, 11, 109-126. [CrossRef] [PubMed]

15. Singh, R.P.; Karmakar, G.P.; Rath, S.K.; Karmakar, N.C.; Pandey, S.R.; Tripathy, T.; Panda, J.; Kannan, K.; Jain, S.K.; Lan, N.T. Biodegradable brag reducing agents and flocculants based on polysaccharides: Materials and applications. Polym. Eng. Sci. 2000, 40, 46-60. [CrossRef]

16. Sorour, M.; El-Sayed, M.; El Moneem, N.A.; Talaat, H.; Shaalan, H.; El Marsafy, S. Free radical grafting kinetics of acrylamide onto a blend of starch/chitosan/alginate. Carbohyd. Polym. 2013, 98, 460-464. [CrossRef] [PubMed]

17. El-Sayed, M.; Sorour, M.; Abd El Moneem, N.; Talaat, H.; Shalaan, H.; El-Marsafy, S. Synthesis and properties of natural polymers-Grafted-acrylamide. World Appl. Sci. J. 2011, 13, 360-368. Available online: https:/ / www.researchgate.net/publication/279704044_Synthesis_and_properties_of_natural_ polymers-grafted-aerylamide (accessed on 30 October 2018).

18. Sadeghi, M.; Heidari, B.; Montazeri, K. pH-Responsiveness properties of a biodigradable hydrogels based on carrageenan-g-poly(NaAA-co-NIPAM). Int. J. Chem. Mol. Nucl. Mater. Metall. Eng. 2011, 5, 301-304. Available online: https:/ / pdfs.semanticscholar.org/1ad2/f872c7e63721a70a78307194ac6c4345afcf.pdf (accessed on 30 October 2018).

19. Shifeng, Y.; Ying, M.; Lucile, M.; Da-Wen, S. Physicochemical properties of starch and flour from different rice cultivars. Food Bioprocess Technol. 2012, 5, 626-637. [CrossRef]

20. Mane, P.C.; Bhosle, A.B.; Jangam, C.M.; Mukate, S.V. Heavy Metal Removal from Aqueous Solution by Opuntia: A Natural Polyelectrolyte. J. Nat. Prod. Plant Resour. 2011, 1, 75-80. Available online: https:/ / www.scholarsresearchlibrary.com/articles/heavy-metal-removal-from-aqueous-solution-byopuntia-a-naturalpolyelectrolyte.pdf (accessed on 30 October 2018).

21. Mane, P.C.; Bhosle, A.B.; Deshmukh, P.D.; Jangam, C.M. Chromium adsorption onto activated carbon derived from Tendu (Diospyros melanoxylon) leaf refuse: Influence of metal/carbon ratio, time and $\mathrm{pH}$. Adv. Appl. Sci. Res. 2010, 1, 212-221. Available online: http://www.imedpub.com/articles/chromiumadsorption-onto-activated-carbon-derived-from-tendu-diospyros-melanoxylon-leaf-refuse-influence-ofmetalcarbon-ratio-time.pdf (accessed on 30 October 2018).

22. Al-Saydeha, S.A.; El-Naas, M.H.; Zaidi, S.J. Copper removal from industrial wastewater: A comprehensive review. J. Ind. Eng. Chem. 2017, 56, 35-44. [CrossRef]

23. Petrovič, A.; Simonič, M. Removal of heavy metal ions from drinking water by alginate-immobilised Chlorella sorokiniana. Int. J. Environ. Sci. Technol. 2016, 13, 1761-1780. [CrossRef] 
24. Mokhter, M.A.; Magnenet, C.; Lakard, S.; Euvrard, M.; Aden, M.; Clément, S.; Mehdi, A.; Lakard, B. Use of Modified Colloids and Membranes to Remove Metal Ions from Contaminated Solutions. Colloids Interfaces 2018, 2, 19. [CrossRef]

25. Sand, A.; Vyas, A.; Gupta, A.K. Graft copolymer based on (sodium alginate-g-acrylamide): Characterization and study of Water swelling capacity, metal ion sorption, flocculation and resistance to biodegradability. Int. J. Biol. Macromol. 2016, 90, 37-43. [CrossRef] [PubMed]

26. Mcneely, W.H.; Pettitt, D.J. Algin. In Industrial Gums: Polysaccharides and Their Derivatives, 2nd ed.; Whistler, R., Ed.; Academic Press: New York, NY, USA, 1973; pp. 49-81, ISBN 978-0-12-746252-3.

27. Manaila, E.; Craciun, G.; Ighigeanu, D.; Campeanu, C.; Barna, C.; Fugaru, V. Hydrogels synthesized by electron beam irradiation for heavy metal adsorption. Materials 2017, 10, 540. [CrossRef] [PubMed]

28. Fiti, M. Dozimetria Chimica a Radiatiilor Ionizante (Ionizing Radiation Chemical Dosimetry), 1st ed.; Editura Academiei Republicii Socialiste Romania: Bucuresti, Romania, 1973; pp. 24-70.

29. Cleland, M.R. Ion Beam Applications. In Proceedings of the Industrial Applications of Electron Accelerators CERN Accelerator School, Zeegse, The Netherlands, 24 May-2 June 2005.

30. Craciun, G.; Manaila, E.; Niculescu, M.; Ighigeanu, D. Obtaining a new type of polyelectrolyte based on acrylamide and hydrolyzed collagen by electron beam irradiation. Polym. Bull. 2017, 74, 1299-1326. [CrossRef]

31. Caulfield, M.J.; Hao, X.; Qiao, G.G.; Solomon, D.H. Degradation on polyacrylamides. Part II. Polyacrylamide gels. Polymer 2003, 44, 3817-3826. [CrossRef]

32. Selvapathy, P.; Reddy, M.J. Effect of polyelectrolytes on turbidity removal. Water Supply 1992, 10, $175-178$. Available online: https://www.researchgate.net/publication/279552053 (accessed on 30 October 2018).

33. Dimonie, M.; Boghina, C.; Cincu, C.; Marinescu, M.; Marinescu, N. Poliacrilamida, 1st ed.; Editura Tehnica: Bucharest, Romania, 1986; pp. 194-208.

34. Caulfield, M.J.; Hao, X.; Qiao, G.G.; Solomon, D.H. Degradation on polyacrylamides. Part I. Linear polyacrylamide. Polymer 2003, 44, 1331-1337. [CrossRef]

35. Sarkar, A.K.; Mandre, N.R.; Panda, A.B.; Pal, S. Amylopectin grafted with poly (acrylic acid): Development and application of a high performance flocculant. Carbohyd. Polym. 2013, 95, 753-759. [CrossRef] [PubMed]

36. Ghosh, S.; Sen, G.; Jha, U.; Pal, S. Novel biodegradable polymeric flocculant based on polyacrylamide-grafted tamarind kernel polysaccharide. Bioresource. Technol. 2010, 101, 9638-9644. [CrossRef] [PubMed]

37. Zhang, S.; Wang, W.; Wang, H.; Qi, W.; Yue, L.; Ye, Q. Synthesis and characterization of starch grafted superabsorbent via $10 \mathrm{MeV}$ electron beam irradiation. Carbohyd. Polym. 2014, 101, 798-803. [CrossRef]

38. Shouman, M.A.; Fathy, N.A.; Khedr, S.A.; Attia, A.A. Comparative Biosorption Studies of Hexavalent Chromium Ion onto Raw and Modified Palm Branches. Adv. Phys. Chem. 2013, 159712. [CrossRef]

39. Liu, C.; Liu, H.; Xiong, T.; Xu, A.; Pan, B.; Tang, K. Graphene Oxide Reinforced Alginate/PVA Double Network Hydrogels for Efficient Dye Removal. Polymers 2018, 10, 835. [CrossRef]

40. Xia, L.; Huang, Z.; Zhong, L.; Xie, F.; Tang, C.Y.; Tsui, C.P. Bagasse Cellulose Grafted with an Amino-Terminated Hyperbranched Polymer for the Removal of $\mathrm{Cr}(\mathrm{VI})$ from Aqueous Solution. Polymers 2018, 10, 931. [CrossRef]

41. Smets, G.; Dysseleer, E. Graft efficiency. Macromol. Chem. Phys. 1966, 91, 160-174. [CrossRef]

42. Xie, C.; Feng, Y.; Cao, W.; Teng, H.; Li, J.; Lu, Z. Novel Biodegradable Flocculating Agents Prepared by Grafting Polyacrylamide to Konjac. J. Appl. Polym. Sci. 2009, 111, 2527-2536. [CrossRef]

43. Khouryieh, H.A.; Herald, T.J.; Aramouni, F.; Alavi, S. Intrinsic viscosity and viscoelastic properties of xanthan/guar mixtures in dilute solutions: Effect of salt concentration on the polymer interactions. Food Res. Int. 2007, 40, 883-893. [CrossRef]

44. Flory, P.J. The structure of vinyl polymers. In Principles of Polymer Chemistry, 1st ed.; Cornell University Press: Ithaca, NY, USA, 1953; pp. 308-314. ISBN 0801401348.

45. Rao, M.A. Rheology of Fluid and Semisolid Foods. Principles and Applications, 2nd ed.; Springer: Berlin/Heidelberg, Germany, 2007; pp. 3-14. ISBN 978-0-387-70929-1.

46. Sadeghi, M.; Godarzi, A.; Khani, F.; Mirdarikvande, S.; Sadeghi, H.; Shasavari, H. Synthesis of a Novel Biopolymer-based alginate Superabsorbent Hydrogel. Bull. Env. Pharmacol. Life Sci. 2014, 3, 169-174. Available online: http:/ / www.bepls.com/bepsljan2014/29a.pdf (accessed on 30 October 2018). 
47. Couto da Feira, J.M.; Klein, J.M.; Camargo Forte, M.M. Ultrasound-assisted synthesis of polyacrylamide-grafted sodium alginate and its application in dye removal. Polímeros 2018, 28, 139-146. [CrossRef]

48. Patel, G.M.; Patel, C.P.; Trivedi, H.C. Ceric-induced grafting of methyl acrylate onto sodium salt of partially carboxymethylated sodium alginate. Eur. Polym. J. 1999, 35, 201-208. [CrossRef]

49. Sun, J.Y.; Zhao, X.; Illeperuma, W.R.K.; Chaudhuri, O.; Oh, K.H.; Mooney, D.J.; Vlassak, J.J.; Suo, Z. Highly stretchable and tough hydrogels. Nature 2012, 489, 133-136. [CrossRef]

50. Manaila, E.; Craciun, G.; Stelescu, M.D.; Ighigeanu, D.; Ficai, M. Radiation vulcanization of natural rubber with polyfunctional monomer. Polym. Bull. 2014, 71, 57-82. [CrossRef]

51. Stelescu, M.D.; Manaila, E.; Craciun, G. Vulcanization of ethylene-propyleneterpolymer-based rubber mixtures by radiation processing. J. Appl. Polym. Sci. 2013, 128, 2325-2336. [CrossRef]

52. Stelescu, M.D.; Manaila, E.; Zuga, N. The use of polyfunctional monomers in the radical cure of chlorinated polyethylene. Polym. J. 2011, 43, 792-800. [CrossRef]

53. Stelescu, M.D.; Manaila, E.; Craciun, G.; Zuga, N. Crosslinking and grafting ethylene vinyl acetate copolymer with accelerated electrons in the presence of polyfunctional monomers. Polym. Bull. 2012, 68, 263-285. [CrossRef]

54. Craciun, G.; Ighigeanu, D.; Manaila, E.; Stelescu, M.D. Synthesis and Characterization of Poly(Acrylamide-Co-Acrylic Acid) Flocculant Obtained by Electron Beam Irradiation. Mater. Res. 2015, 18, 984-993. [CrossRef]

55. Alberti, A.; Bertini, S.; Gastaldi, G.; Iannaccone, N.; Macciantelli, D.; Torri, G.; Vismara, E. Electron beam irradiated textile cellulose fibres: ESR studies and derivatisation with glycidyl methacrylate (GMA). Eur. Polym. J. 2005, 41, 1787-1797. [CrossRef]

56. Isiklan, N.; Kursun, F. Synthesis and characterization of graft copolymer of sodium alginate and poly(itaconic acid) by the redox system. Polym. Bull. 2014, 70, 1065-1084. [CrossRef]

57. Bisval, D.R.; Sing, R.P. Flocculation studies based on water soluble polymers of grafted carboxymethyl cellulose and polyacrylamide. J. Appl. Polym. Sci. 2006, 102, 1000-1007. [CrossRef]

58. Sharma, B.R.; Dhuldhoya, N.C.; Merchant, U.C. Flocculants-an Ecofriendly Approach. J. Polym. Environ. 2006, 14, 195-202. [CrossRef]

59. Laue, C.; Hunkeler, D. Chitosan-graft-acrylamide polyelectrolytes: Synthesis, flocculation and modeling. J. Appl. Polym. Sci. 2006, 102, 885-896. [CrossRef]

60. Munoz Prieto, E.J.; Rivas, B.; Sanchez, J. Natural polymer grafted with synthetic monomer by microwave for water treatment- A review. Rev. Ciencia Desarrollo 2012, 4, 219-240. [CrossRef]

61. Zhang, W.; Shang, Y.; Yuan, B.; Jiang, Y.; Lu, Y.; Qin, Z.; Chen, A.; Qian, X.; Yang, H.; Cheng, R. The flocculating properties of chitosan-graft-polyacrylamide flocculants (II)—Test in pilot scale. J. Appl. Polym. Sci. 2010, 117, 2016-2024. [CrossRef]

62. Kumar, K.; Das, D. Growth characteristics of Chlorella sorokiniana in airlift and bubble column photobioreactors. Bioresour. Technol. 2012, 16, 307-313. [CrossRef] [PubMed]

63. Onyancha, D.; Mavura, W.; Ngila, J.C.; Ongoma, P.; Chacha, J. Studies of chromium removal from tannery wastewaters by algae biosorbents, Spirogyra condensata and Rhizoclonium hieroglyphicum. J. Hazard. Mater. 2008, 158, 605-614. [CrossRef] [PubMed]

64. Wu, N.; Wei, H.; Zhang, L. Efficient Removal of Heavy Metal Ions with Biopolymer Template Synthesized Mesoporous Titania Beads of Hundreds of Micrometers Size. Environ. Sci. Technol. 2012, 46, 419-425. [CrossRef] [PubMed]

(C) 2019 by the authors. Licensee MDPI, Basel, Switzerland. This article is an open access article distributed under the terms and conditions of the Creative Commons Attribution (CC BY) license (http://creativecommons.org/licenses/by/4.0/). 